\title{
Kuk Swamp
}

\section{Philip Hughes, Tim Denham and Jack Golson}

\section{The Wahgi Valley}

Kuk Swamp lies at around $1580 \mathrm{~m}$ altitude in the upper Wahgi Valley, a large intermontane basin between the Sepik-Wahgi Divide to the north and the Kubor Range to the south, both of which rise to $4000 \mathrm{~m}$ or more above sea level. Today the basin is largely drained by the east-flowing Wahgi River, but formerly the western part drained westwards. This drainage was reversed with the damming of the valley by a massive volcanic debris avalanche from the Mt Hagen stratovolcano, which today dominates the western end of the basin, rising about $2000 \mathrm{~m}$ above the surrounding landscape (Löffler 1977: 26-27, 73; Pain et al. 1987). The avalanche responsible for this blockage occurred at least $80-100,000$ and possibly 400,000 years ago (Pain et al. 1987: 275).

The Wahgi Basin is filled with extensive fan and terrace deposits that, at the western end of the valley, at the point where it is widest, are capped with swampland in the ponded area between the footslopes of Mt Hagen and the higher fans and terraces to the east (Haantjens et al. 1970: 22; Löffler 1977: 105-107; Pain et al. 1987: 269, Fig. 2). In their natural state, these swamplands were more than $250 \mathrm{~km}^{2}$ in area (Haantjens, Reiner and Robbins 1970: 64-65; Pain et al. 1987: Fig. 2). They covered large areas of floodplain along the upper reaches of the Wahgi River and its tributaries and accumulated as extensive back swamps between the floodplain and adjacent higher ground (Fig. 6.1 below). Over much of the area, the swamplands were discontinuous and relatively shallow (probably $<2 \mathrm{~m}$ ). There are two major swamp basins, the huge North Wahgi Swamp and a smaller swamp basin to the south, of which Kuk Swamp is part (Pain et al. 1987: 271, Fig. 2). These two basins are separated by a major bedrock ridge called Ep. Being virtually surrounded by water, Ep Ridge was called the 'island' by the first Europeans to enter the upper Wahgi (cf. Leahy 1936: 248; Gorecki 1979b: 26).

Beginning in the 1950s, large parts of the Wahgi swamplands were progressively drained and the land developed for agricultural purposes, mainly tea and coffee plantations. The Kuk Tea Research Station was established at Kuk Swamp in 1969. 


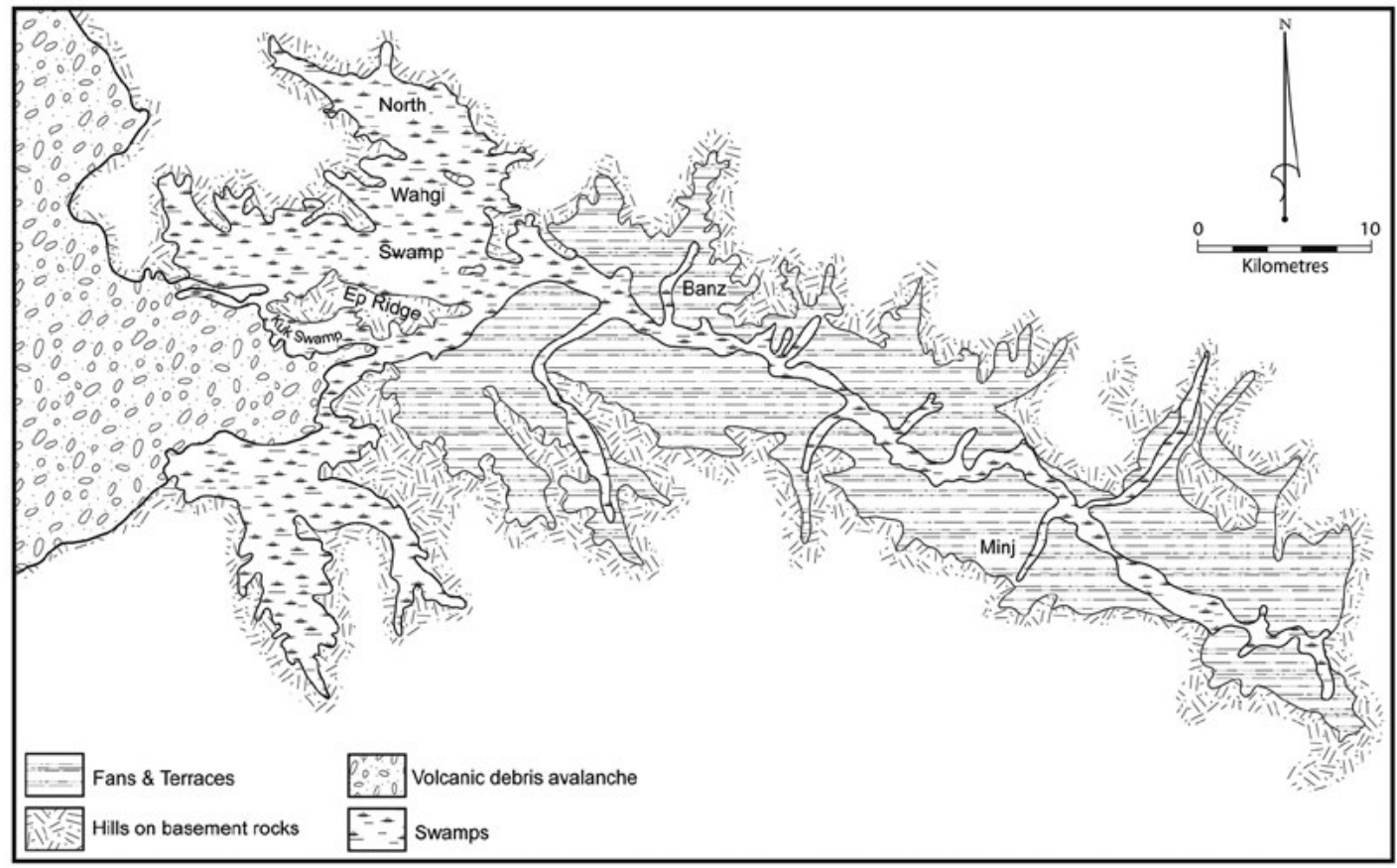

Figure 6.1 The swamplands of the Wahgi Valley before large-scale drainage began in the $1950 \mathrm{~s}$.

Source: After Pain et al. (1987: Fig. 2). Drawing by Kara Rasmanis.

\section{Kuk Swamp in its local setting}

To the immediate north of the swamp, the steep slopes of Ep Ridge rise 150-350 m above it (Figs 6.2 and 6.3). To the south are low hills formed on volcanic debris avalanche (lahar) deposits derived from Mt Hagen to the west (Blong 1986a; Pain et al. 1987; Figs 6.1, 6.4, 6.5, 6.6 and 6.7 here). These lahar deposits are capped by a sequence of up to nine volcanic ash (or tephra) formations older than 50,000 years, all most probably derived from Mt Hagen (Pain and Blong 1976). The tephra cover on the hills is commonly less than $1 \mathrm{~m}$, but it is much thicker on their flanks. In the east of the Station, the gently undulating tephra-mantled land surface dips northwards, and then also northwestwards, beneath the deposits of the swamp, with a few low rises or hills of about $1 \mathrm{~m}$ local relief (Figs 6.2, 6.4 and 6.5). In the southwest of the Station, the tephra-mantled land surface is visible as an extensive area of slightly higher ground narrowing to the north (Fig. 6.4).

The swamp surface slopes down a couple of metres from the southern boundary of the Station, relatively steeply at first, then almost imperceptibly, to its lowest point about two-thirds of the way across the swamp. Northwards of this it rises quite sharply over the toes of the fans at the base of Ep Ridge (Figs 6.4, 6.8 and 6.9). This situation reflects the greater influence on depositional processes in the swamp basin of water coming from the southern catchment than that of the very much shorter but steeper northern catchments on Ep Ridge (Fig. 6.2). 


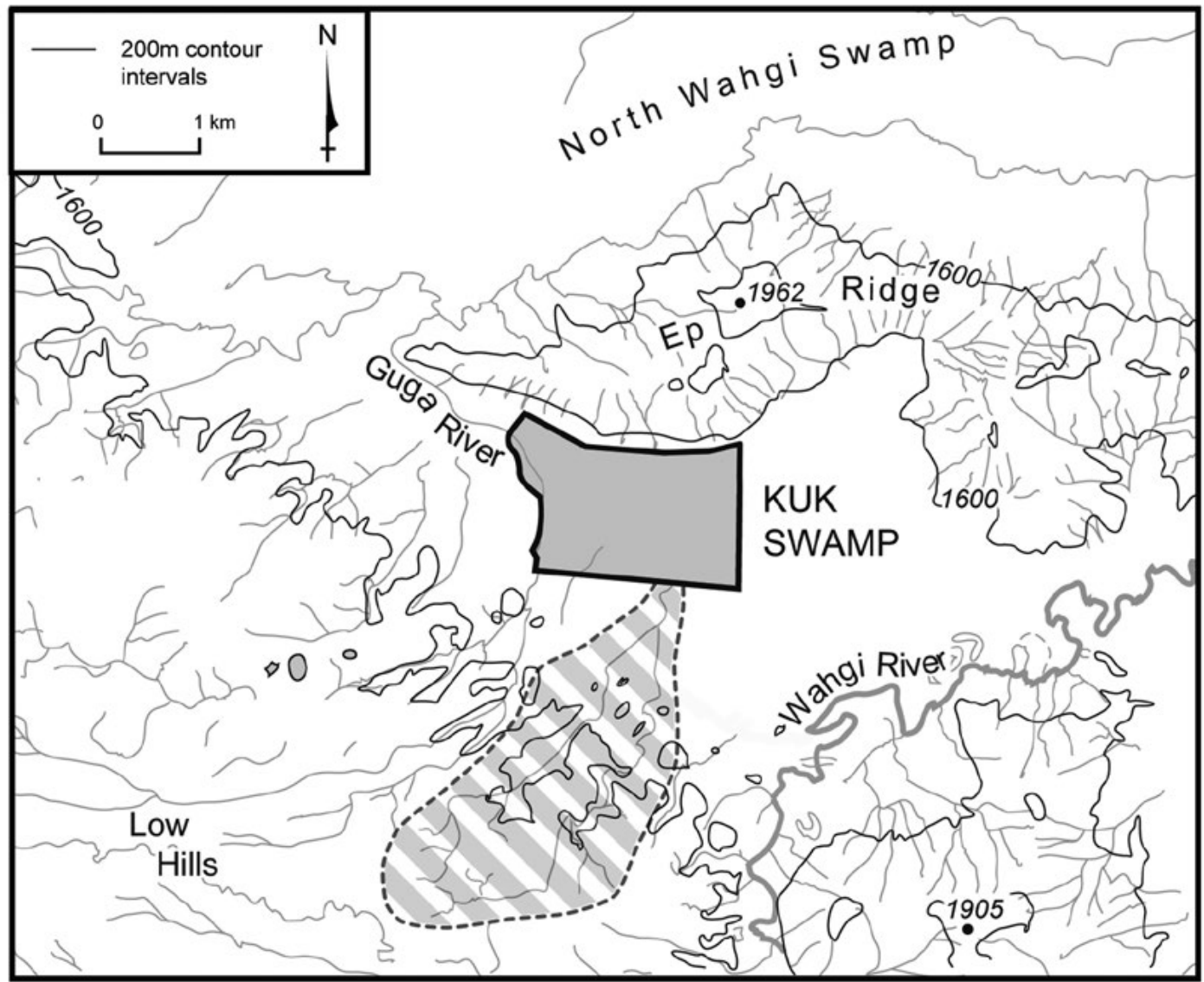

Figure 6.2 Kuk Research Station and its landscape setting, showing the southern catchment of Kuk Swamp (shaded).

Source: Drawing by Harrison Pitts.

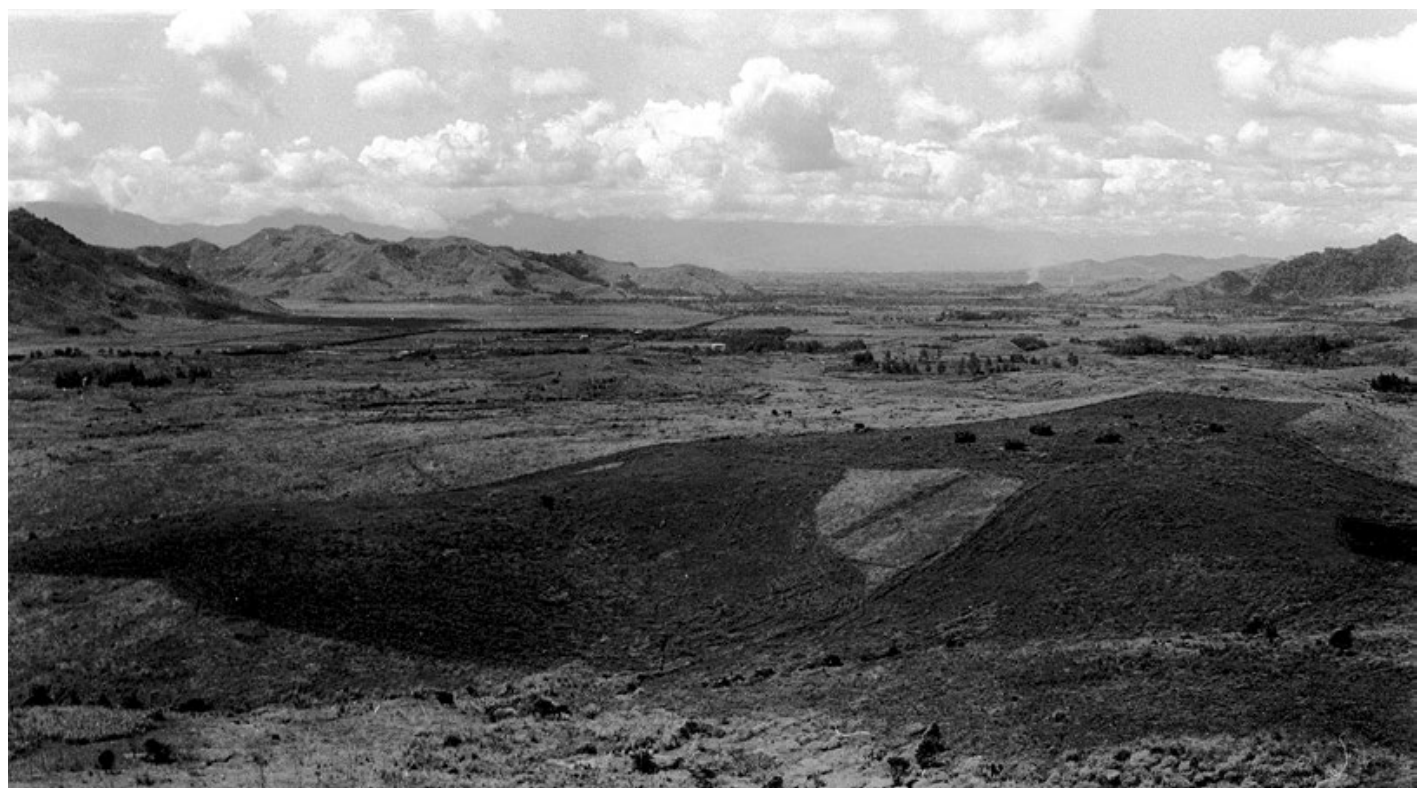

Figure 6.3 Looking east down the Wahgi Valley to Kuk from Mt Ambra. The slopes of Ep Ridge are on the extreme left edge.

Source: Photograph by Ole Christensen, Kuk archive, 1973. 


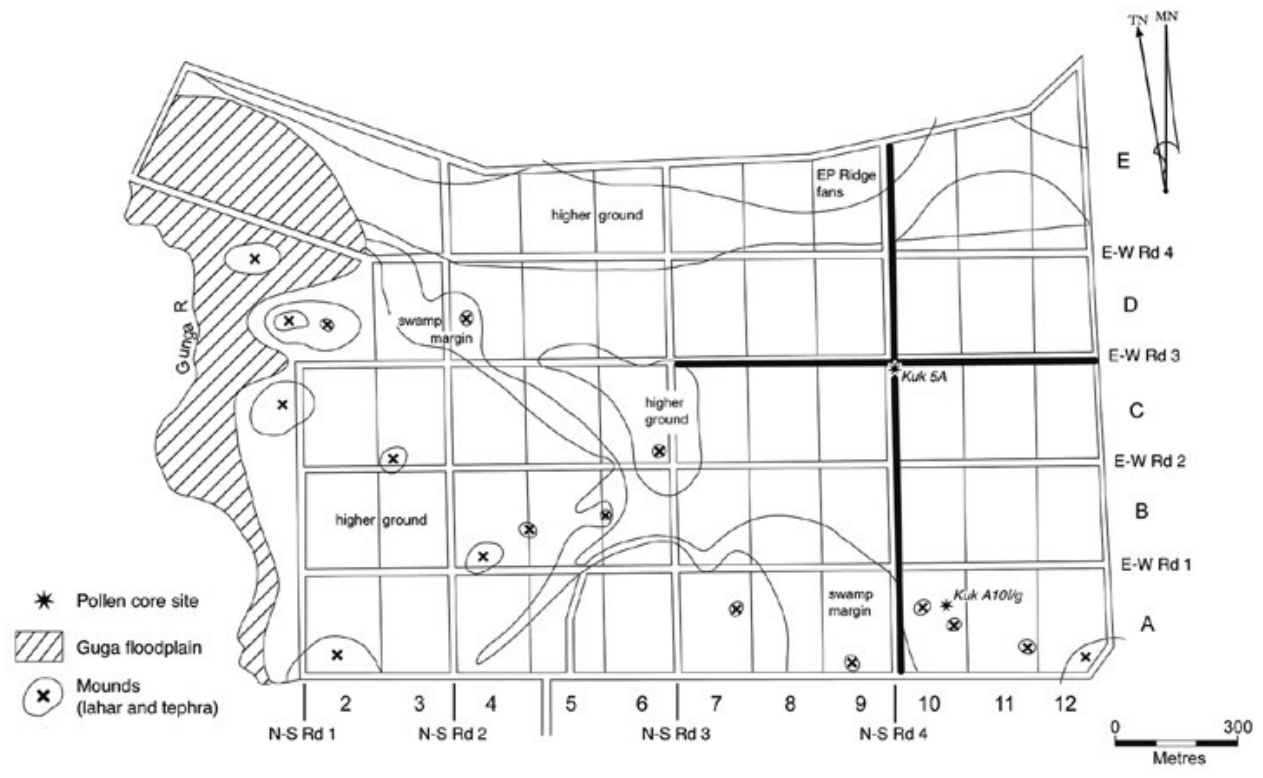

Figure 6.4 Landforms of Kuk Swamp.

The black lines show the location of the stratigraphic profiles illustrated in Figure 6.9. The north-south profile marks the approximate position of the watershed. The locations of the two pollen cores, Kuk 5A and Kuk A10f/g (Powell 1984), described in Chapter 9 are also shown.

Source: Drawing by Winifred Mumford.

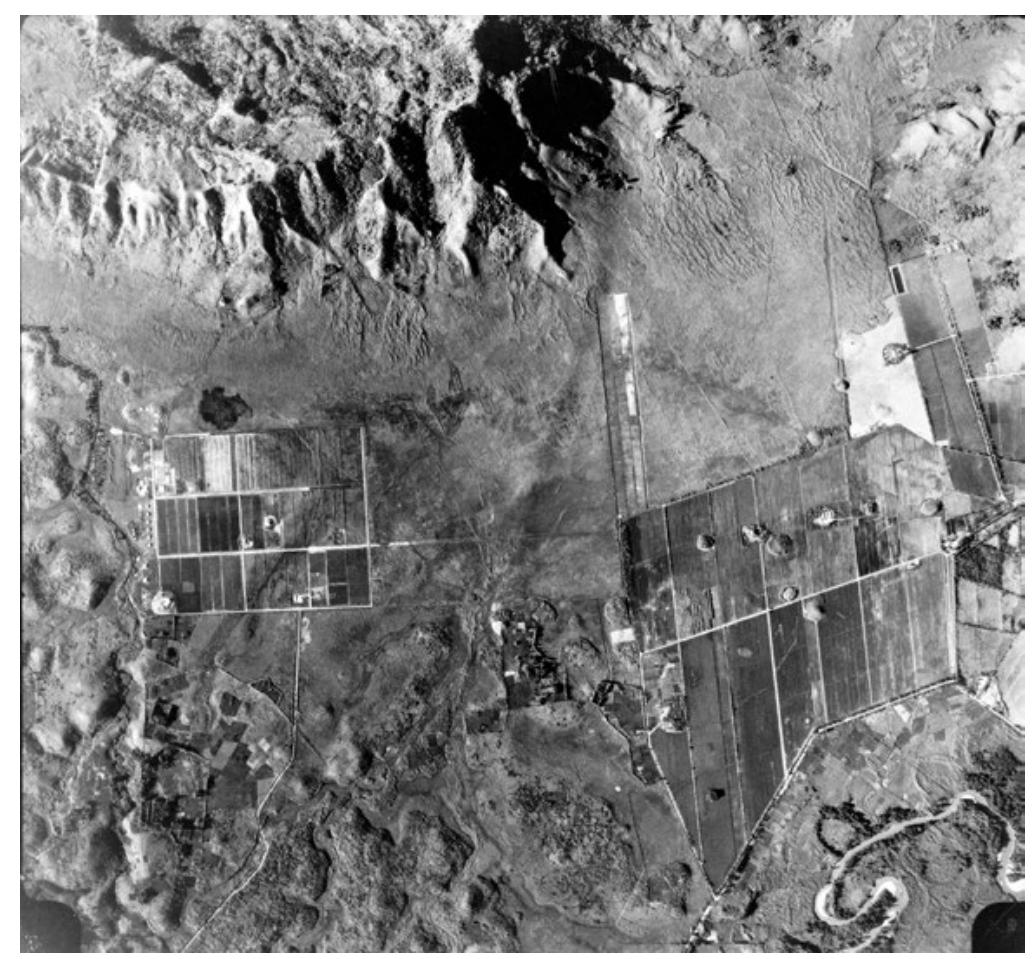

Figure 6.5 Vertical aerial photograph of Kuk Swamp and its surrounds in 1970, including Ep Ridge to the north and the low hilly catchment to the south.

The SW part of the agricultural station is under development and to the SE is Tibi tea plantation. Some of the hills to the south and west of Kuk are lahar mounds and there are several prominent lahar mounds at the northern end of Tibi plantation.

Source: Qasco aerial photograph, 5 0ctober 1970, Film NG 127, Run 4, reproduced with permission.

\section{terra australis 46}




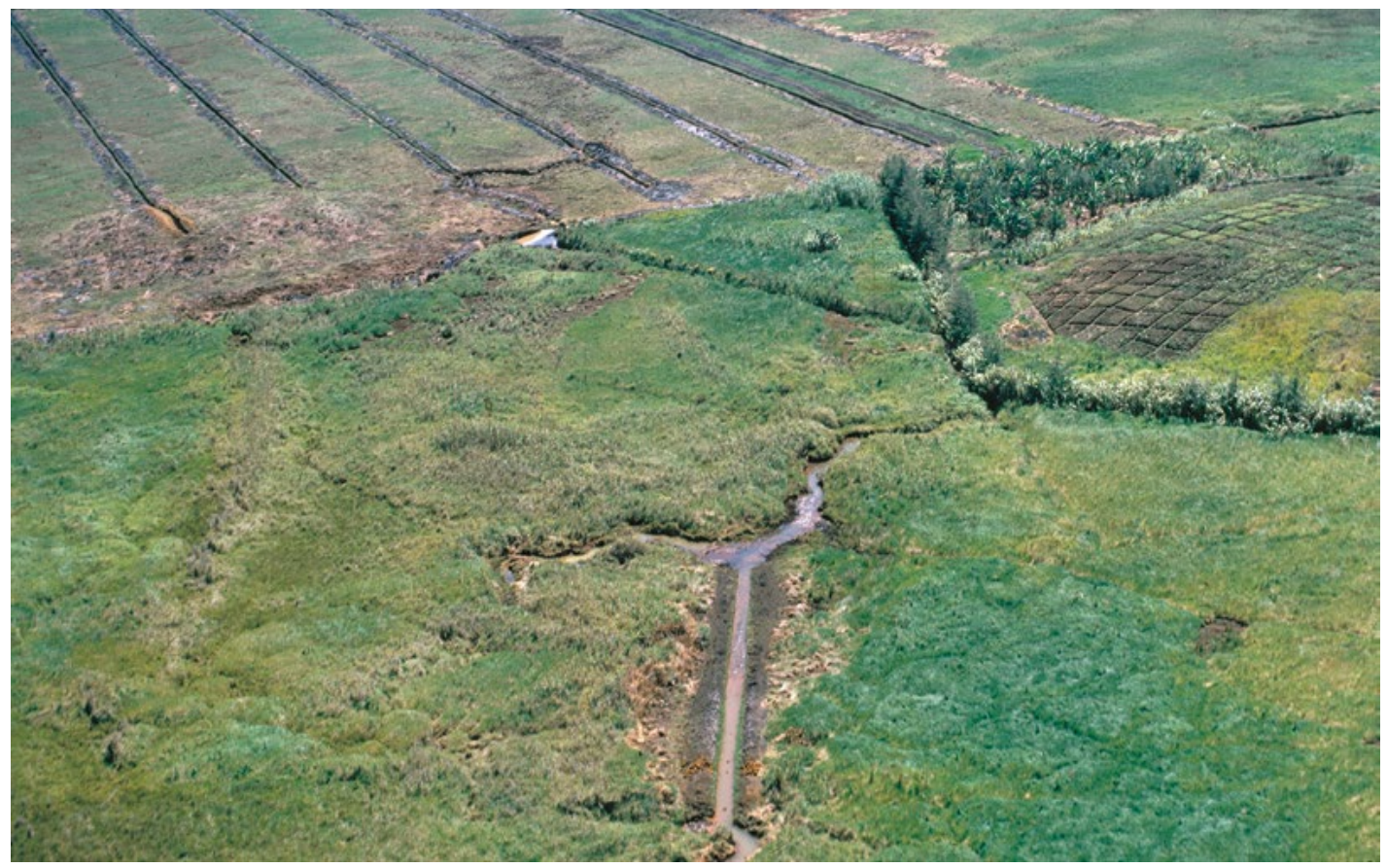

Figure 6.6 Oblique aerial photograph of the Kuk Swamp southern catchment, looking NE over the Station's southern boundary drain.

The southern end of the most westerly of the Station drains cuts into a lahar mound we called 'Blong's Nob'. The two close-set drains to the east are the flanking drains for the future N-S Rd 4 of the Station grid. At the top left of the photograph is E-W Rd 1. Source: Photograph by Russell Blong, Kuk archive, 1972.

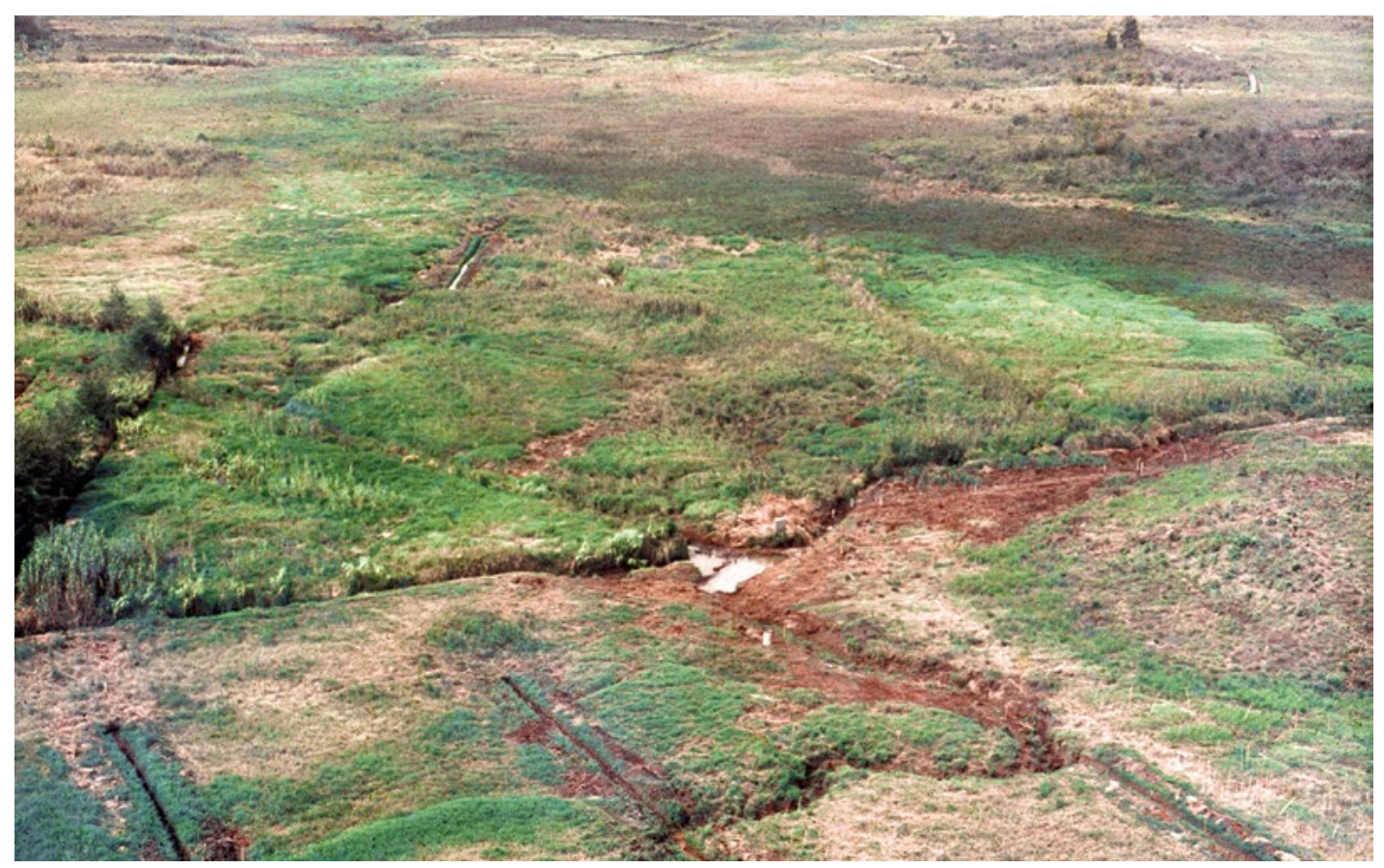

Figure 6.7 Oblique aerial photograph of the Kuk Swamp southern catchment, looking SSW over the southern boundary drain. Blong's Nob appears just above the bottom right corner of the photograph. Source: Photograph by Wal Ambrose, Kuk archive, 1972. 


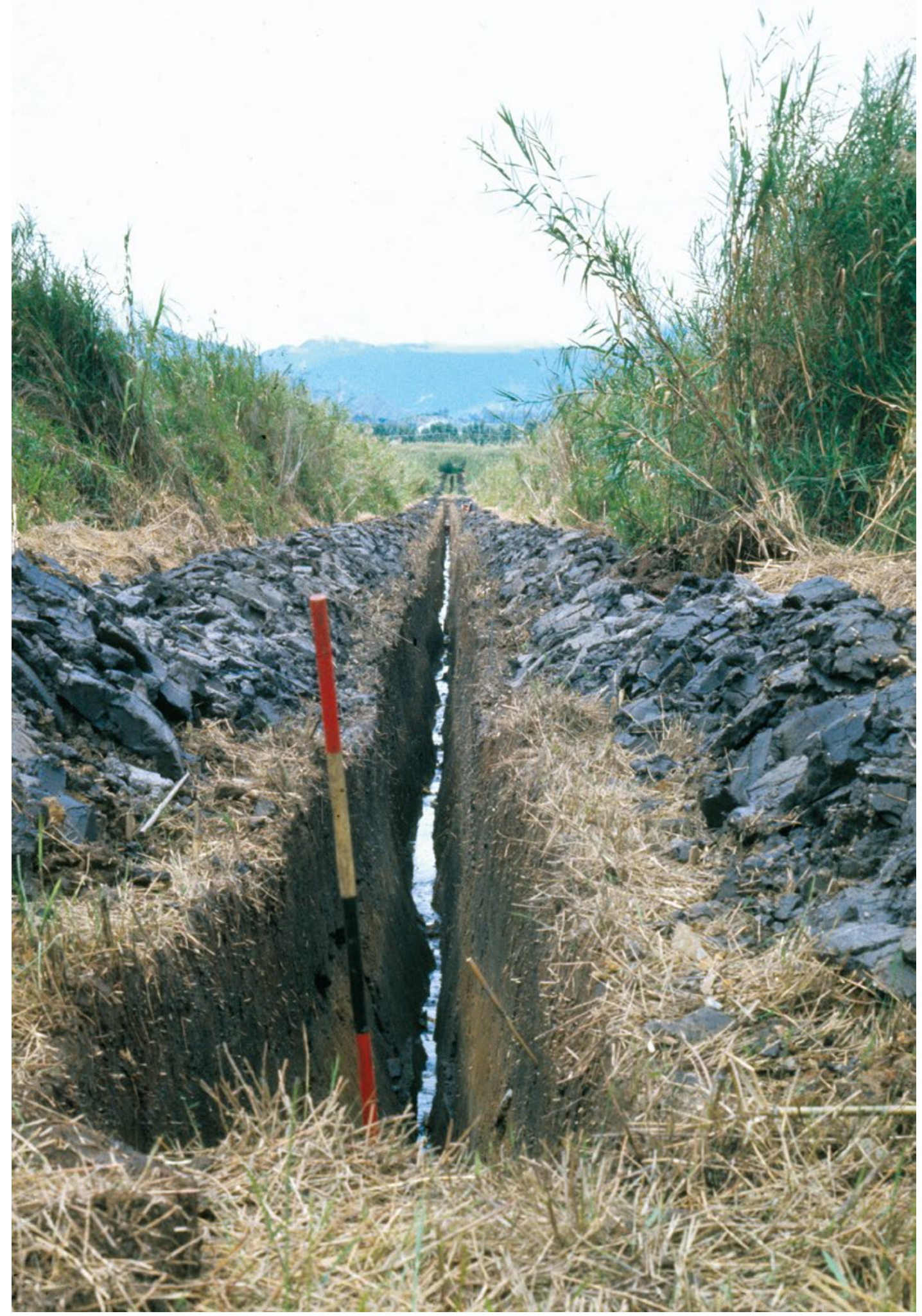

Figure 6.8 Looking south from the foot of Ep Ridge along drain E7f/g towards the line of trees bordering E-W Rd 1. Drain D7f $/ g$ is in the background.

Source: Photograph by Philip Hughes, Kuk archive, 1975. 
$\mathrm{N}$
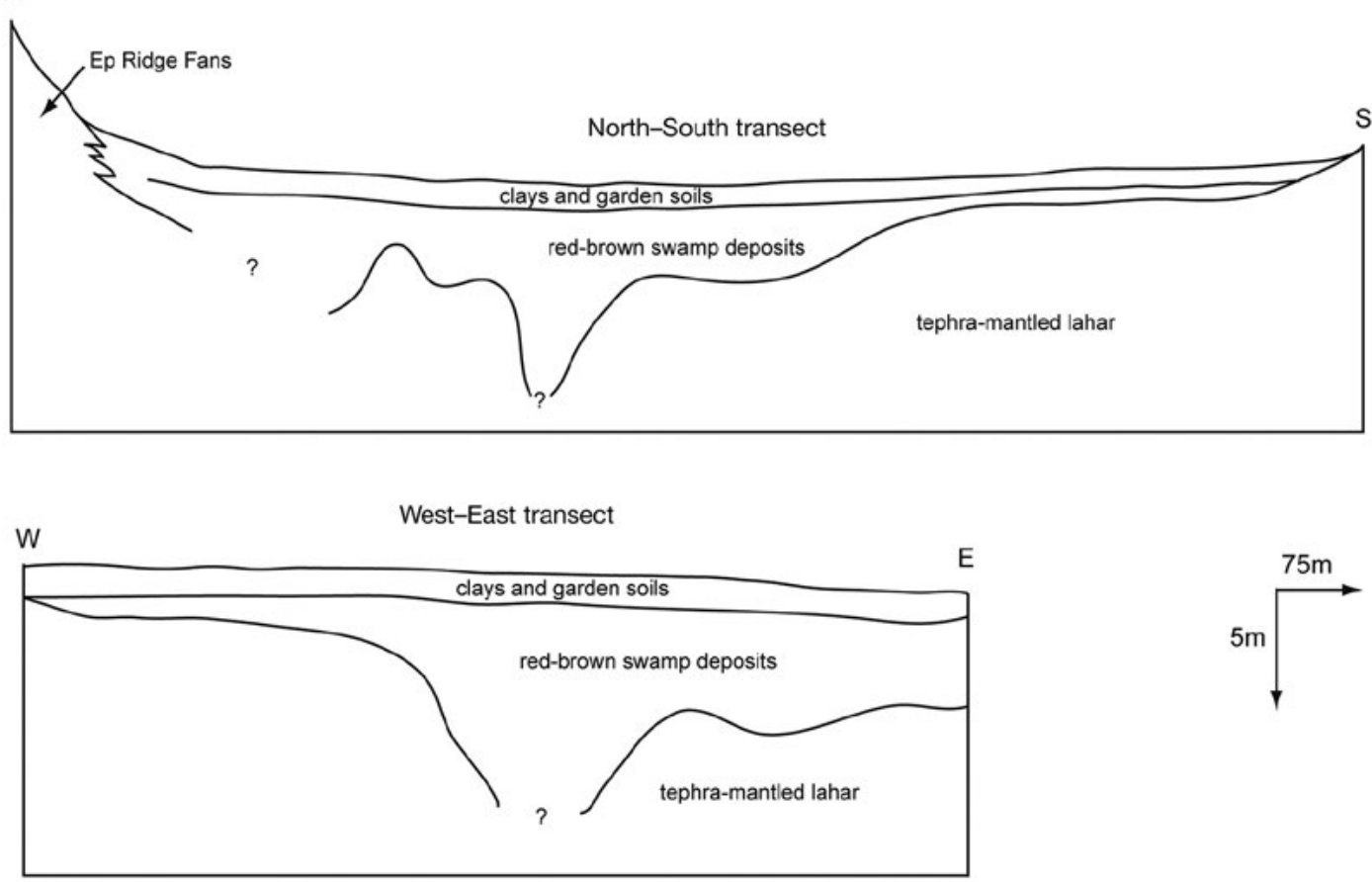

Figure 6.9 Stratigraphic profiles across the eastern half of Kuk Station, showing the thickness of the swamp deposits.

The north-south transect is along the eastern drain of N-S Rd 4 and the east-west transect along the southern drain of E-W Rd 3 (see Fig. 6.4).

Source: Kay Dancey, CartogIS Services, College of Asia and the Pacific, ANU.

There is a watershed running north across the widest part of the swamp in the eastern part of the Station (Fig. 6.4), imperceptible to the naked eye but known to some of the older Kawelka residents of the area. Under natural conditions the water that drained eastwards flowed across the large tracts of adjacent swampland, known locally today as Tibi, Tibi Residue and Baisu, and thence along a shallow valley through higher ground and into the Wahgi River (Fig. 6.2). Water draining westwards moved via the Guga River to the Gumants River, which in turn flowed through the vast North Wahgi Swamp, eventually reaching the Wahgi River well downstream to the east (Figs 6.2 and 6.4). The existence of this watershed was recognised during early planning for the Kuk drainage scheme (McGrigor n.d.).

During this planning phase some areas of the swamp were found to be over $10 \mathrm{~m}$ deep, making them amongst the deepest such deposits in the Wahgi Valley (McGrigor n.d.). The thickness of swamp deposits overlying the tephra-mantled basement was documented in cores by Jocelyn Powell in the early stages of the Kuk Project; the reconstructed cross-sectional profiles show that before the present swamp formed, a shallow valley at least $6 \mathrm{~m}$ (and probably more than $10 \mathrm{~m}$ ) deep and $100 \mathrm{~m}$ wide had been cut by stream action into the plain that existed at that time (Fig. 6.9). The reasons why this and any other streams draining the basin ceased to flow freely, thus allowing swamp to accumulate, are not known. It could have been caused by landslides or accumulating fan deposits from Ep Ridge that blocked the Guga River outlet to the west and deposition on the Wahgi River floodplain that cut off drainage to the east (Fig. 6.2).

Overall, Kuk Swamp is a shallow basin (Figs 6.2, 6.4 and 6.9) into which sediment was washing from the surrounding hills for more than 50,000 years, along with the decayed remains of plants that grew in the swamp. In the process, the swamp deposits have come to consist of a sequence 
of distinctive layers of organic and inorganic sediments: deeper deposits reflect changing regional and local climatic and hydrological conditions; shallower deposits primarily reflect the impacts of human landuse in the dryland catchments of the swamp and in the swamp itself over the last 10,000 years.

The stratigraphy of the swamp has been recorded along more than $15 \mathrm{~km}$ of modern drainage ditches over an area of about 100 ha covering many parts of the Station, especially the eastern half (Fig. 6.4). The ages of the stratigraphic units shown in Figure 6.10 have been determined from widespread radiocarbon dating and from the swamp-wide correlation of a number of thin, highly distinctive airfall tephras that are preserved in the deposits (see Chapter 7). In the southeastern part of the swamp, the increasingly inorganic sediments deposited after about 20,000 years ago comprise a fan deposit (Fig. 6.11), thickest at the southern margin of the swamp, which formed from sediments washed in from the low tephra-mantled hills to the south (Figs 6.2 and 6.5). Numerous similar but smaller and steeper fans deriving from Ep Ridge protrude into the swamp from the north.

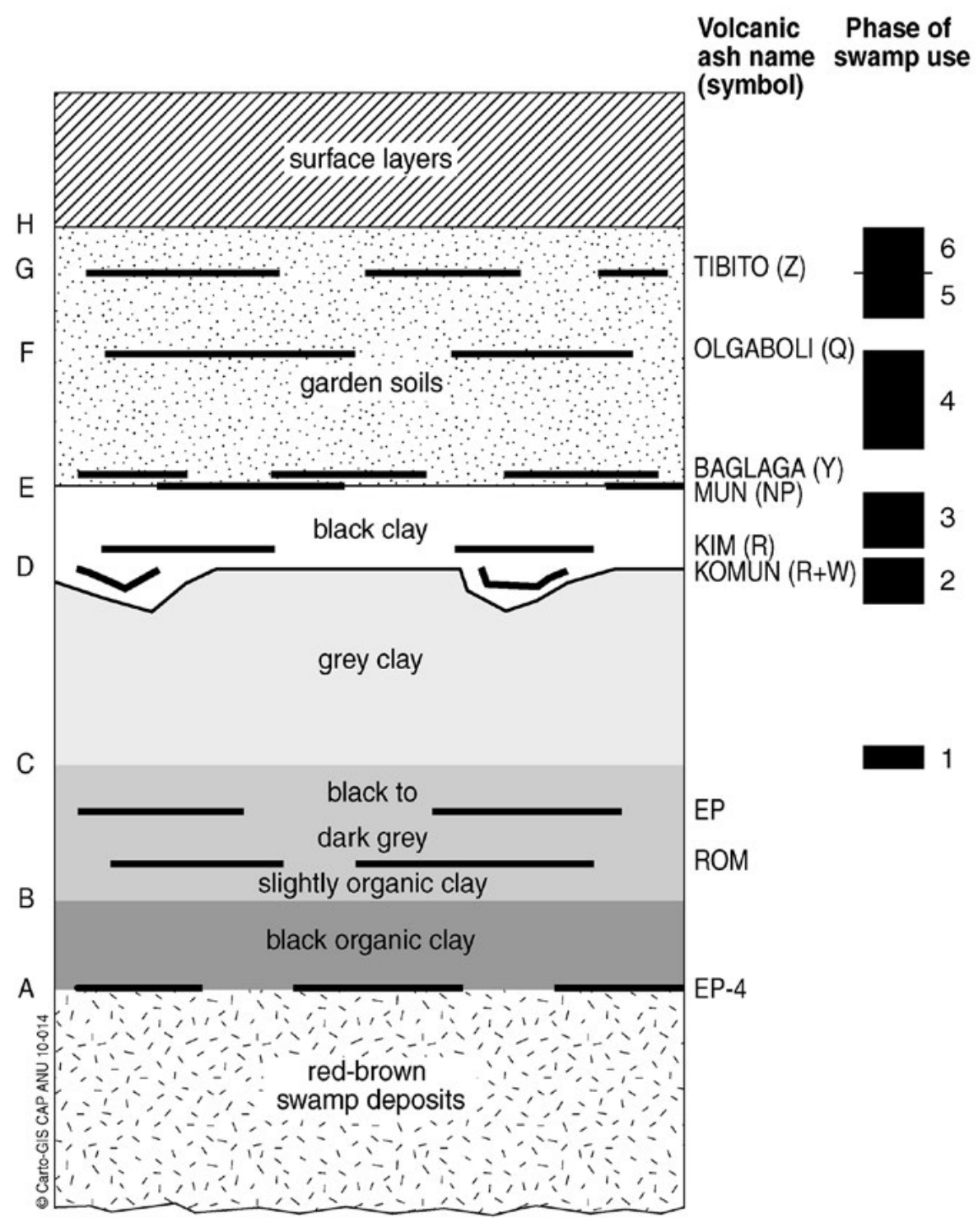

Figure 6.10 Schematic diagram of the main stratigraphic units and some tephras at Kuk Swamp. Source: Kay Dancey, CartoGIS Services, College of Asia and the Pacific, ANU. 


\section{Main stratigraphic units at Kuk}

There are seven main stratigraphic units and nine tephras identified at Kuk (Figure 6.10). With the exception of $\mathrm{G}$, the chronology in the discussion that follows is based on radiocarbon dates calibrated to years Before Present (BP) at two standard deviations. See Table 7.2 for dates of B, F and $G$. The ages of the main stratigraphic units and their associated tephras are described as follows: ${ }^{1}$

- A is the transition from red-brown swamp deposits to black organic clay, marked in places by a volcanic ash (or tephra) called Ep-4. A generalised minimum age of 35,000 years for the transition, and thus for Ep-4, is argued in Appendix 6.1.

- B marks the transition from black organic clay to black to dark grey slightly organic clay, which on drain D7d/e is spanned by a $150 \mathrm{~mm}$ diameter log some $15 \mathrm{~m}$ south of the north end of the drain. The log is dated by ANU-3186 to between 24,650 and 23,380 BP (see Rom tephra in Chapter 7).

- C marks the start of grey clay deposition between a date in the range 10,220-9910 BP for the top of the fill of channel 101, which the grey clay overlies, and one in the range 10,230-9780 BP from near the base of the grey clay itself (see Denham et al. 2003: Table S2; Table S1 gives the individual radiocarbon dates).

- D, the horizon between grey and black clay, falls between a date in the range 7420-7210 BP near the top of grey clay (Denham et al. 2003: Table S1, OZD931) and one in the range 6950-6440 BP near the base of black clay (Denham et al. 2003: Table S2; see Table S1 for the individual radiocarbon dates).

- E, the horizon between black clay and garden soils, is marked in places by Mun (Niupela) tephra. The ashfall is undated, but occurred between a date in the range 2730-2360 BP for a late phase of black clay formation and one in the range 2710-2120 BP for the surface on which Baglaga (Y) tephra fell (Denham et al. 2003: Table S1, ANU-8056 and 8057 respectively). A new date is in the range 2700-2340 BP for the surface below Baglaga at nearby Mt Ambra crater (Sniderman, Finn and Denham 2009: Table 2, OZF145). For Baglaga dates see Table 7. 2.

- F is Olgaboli Tephra (Q), dated between 1230 and 970 BP. At around this level in the profile, the garden soils change in texture from finer to coarser.

- $\mathrm{G}$ is Tibito Tephra (Z), dated between 304 and 154 BP by radiocarbon (the calibrations in this case not rounded off) and $\mathrm{AD}$ 1665/1666 on other evidence.

- $\mathrm{H}$ is the base of the surface layers of peat, and its decay products, that formed over the swamp after gardening ceased. This was shortly before the fall of Tibito Tephra in the deeper swamp and in the early 20th century elsewhere at Kuk.

From broader geomorphic investigations across the entire Station, it was possible to map areas comprising what were referred to in the field as 'true swamp', 'swamp margin' and 'higher ground' (Fig. 6.4). 'True swamp' was that area where the basement deposits were mantled with red-brown swamp deposits older than about 35,000 years, as described below. 'Higher ground' referred to that part of the Station where, if they occurred at all, any overlying swamp deposits were thin $(<0.5 \mathrm{~m})$ and had been converted into garden soil over the last 2500 years or so. 'Swamp margin' was the land between these two. Also mapped were 'mounds' (Fig. 6.4; cf. Figs 6.5 and 6.12), small hills formed from tephra older than 50,000 years. The cores of some of these were seen to consist of lahar deposits and therefore they can properly be called 'lahar mounds' (Fig. 6.6; cf. Fig. 6.5). At least one other low hill, which was exposed in section to a depth of almost $3 \mathrm{~m}$, consisted of tephra-derived clay without any sign of lahar material (Fig. 6.13). This, and other possible examples of the same type, may be residual features formed by erosion of the original volcanic landscape.

1 The tephras were named after localities in the Wahgi Valley. Most of them originally were given fieldnames (shown here in brackets after the formal names), which, because these were used in many of the earlier Kuk publications, are reproduced here for consistency. For the use of upper case T for Tephra following Olgaboli and Tibito see Chapter 7. 
Surface layers, garden soils \& black clay

$\square$ Grey clay

Black to dark grey slightly organic clay \& black organic clay

$\because:$ Red-brown swamp deposits

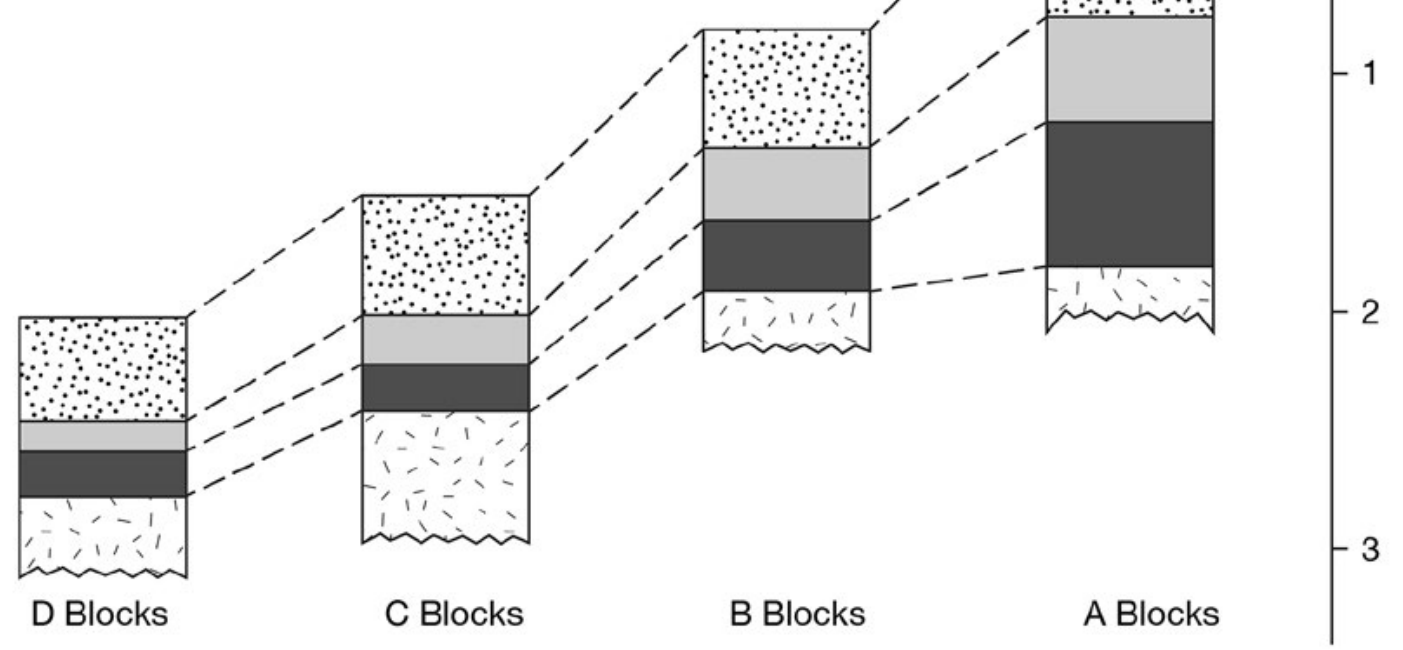

Figure 6.11 The relative disposition of major stratigraphic units in the SE part of Kuk Swamp.

Based on records taken along Station drains in blocks to the east and west of N-S Rd 4. See also Figures 6.17, 6.18 and 6.19. Source: Jennifer Sheehan, CartoGIS Services, College of Asia and the Pacific, ANU.

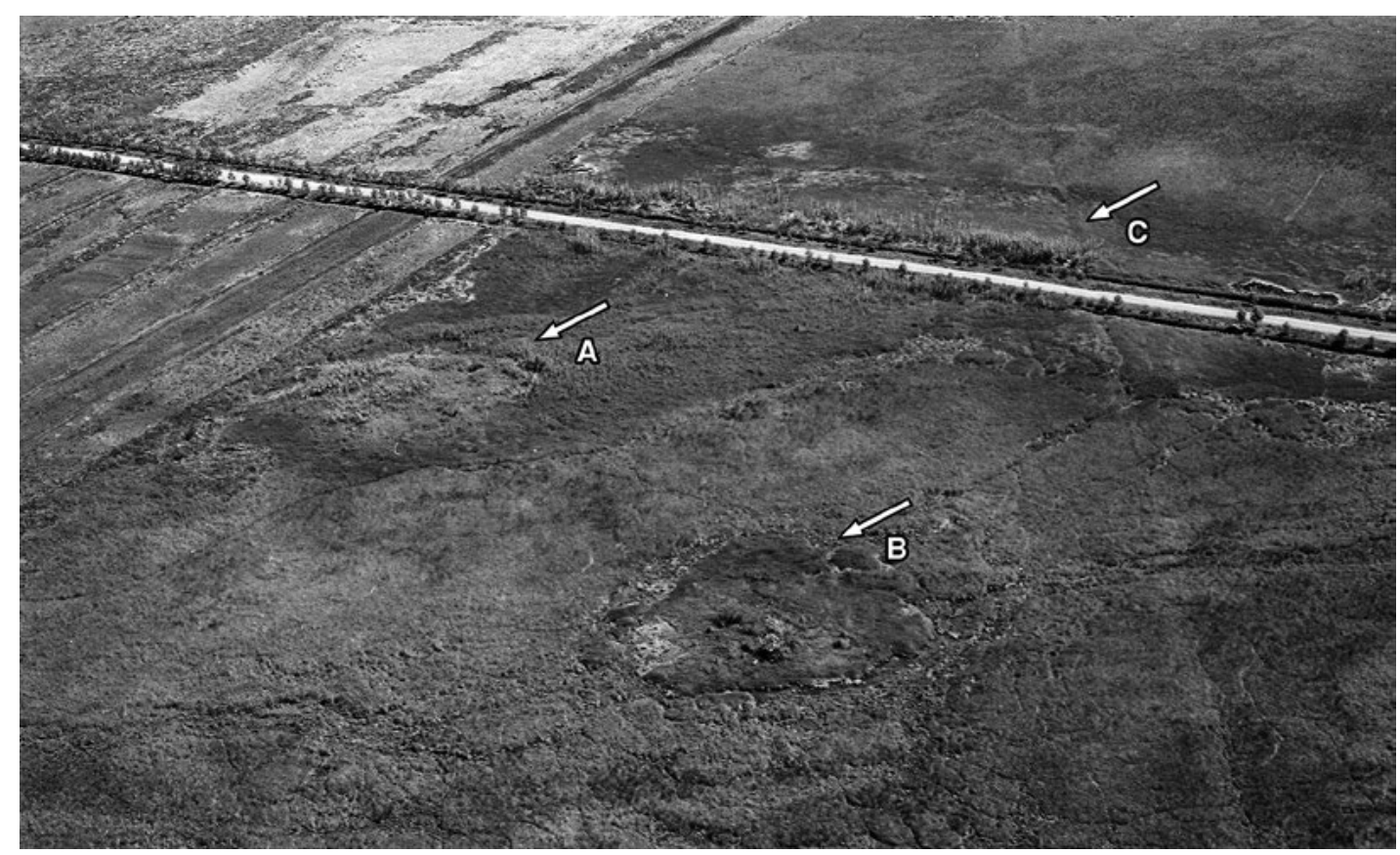

Figure 6.12 Oblique aerial photograph of two tephra mounds in block A10 (arrows A and B), view to NW. The straight line to the east of the mounds is the course of Simon's Baret (arrow C), a disposal channel of Phases 5 and 6 running NNW from beyond the Station southern boundary.

Source: Photograph by Wal Ambrose, Kuk archive, 1972. 


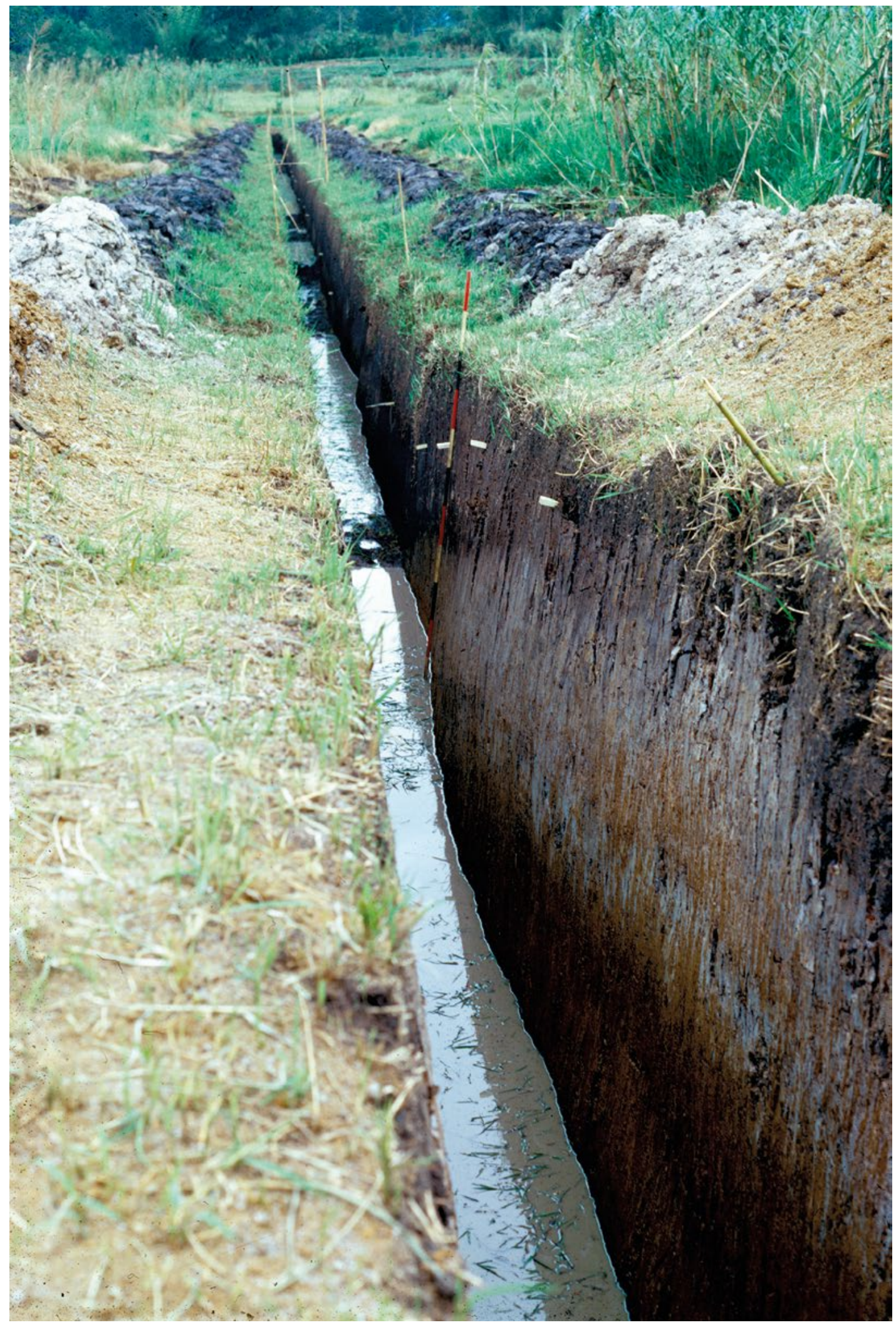

Figure 6.13 Stratigraphy viewed from the north in drain A10f/g, which was dug through the tephra hill marked B in Figure 6.12.

Source: Photograph by Philip Hughes, Kuk archive, 1974. 


\section{Kuk Swamp and its drainage for the Research Station}

The following description of Kuk Swamp and its drainage for the establishment of a Tea Research Station in 1969 by the Australian administration's Department of Agriculture, Stock and Fisheries is based on two unpublished documents by Alan McGrigor (n.d., 1969), who was responsible for the drainage works. They give different figures for the area of the Station: 770 acres in an undated document, which converts to $311.6 \mathrm{ha}$, and 318.4 ha in the other. We adopt 311 ha for the area, since this is close to the figure others have used (e.g. Ketan 1998: 18; Moutu 1998: 20). Some 75 per cent of the property was described as peat swamp under a cover of either phragmites (Phragmites karka), sedge (probably several species including Eleocharis sphacelata) or both. The remaining 25 per cent consisted mainly of slightly elevated land in the southwest sector, still only poorly drained at best, and the lower slopes of Ep Ridge within the Station, which would have been relatively well drained. There were no watercourses as such on the block, only sluggish flow lines. McGrigor (1969: 2) estimated that at least 50-60 per cent of the area would have been permanently under water. Conditions over much of the block were such that the surface would not support the weight of a person, but there was a firm 'bottom' between about $0.3 \mathrm{~m}$ and $2 \mathrm{~m}$ below the surface. As discussed below, in many places the swamp surface apparently consisted of floating mats of vegetation.

Before beginning the internal drainage of the Station, it was necessary to collect and dispose of the water entering the block from outside its boundaries. According to McGrigor's estimates, Ep Ridge contributed the runoff from some 120 ha of catchment above the northern boundary, most of which was taken by small incised streams down the steep slopes. Most of the runoff from 464 ha of undulating country beyond the southern boundary, on the other hand, was carried by two creeks; the eastern one, Tibi Creek, draining a much larger area than the western one, Tibito Creek. The southern boundary drain of the Station was dug to intercept the eastern creek (Figs 6.6 and 6.7). Water was taken by the southern and eastern boundary drains into the Tibi drainage system and eastwards across Baisu to the Wahgi River. The flow of the more westerly of the two creeks was formalised to take its water along internal drains of the Station and into the Guga Creek at its western boundary (Fig. 6.14).

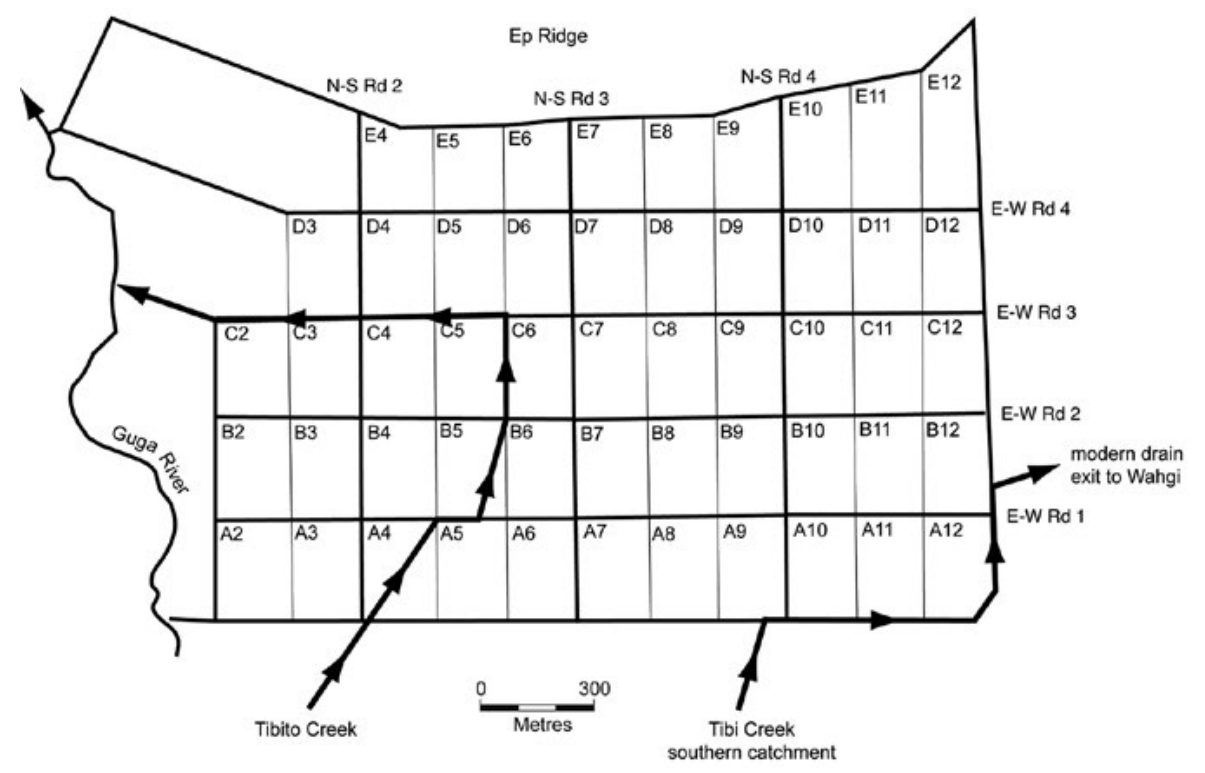

Figure 6.14 Schematic map depicting the road and block grid at Kuk Research Station. The main outlet drains diverting flow to the east from Tibi Creek and to the west from Tibito Creek are also shown.

Source: Kay Dancey, Cartogis Services, College of Asia and the Pacific, ANU.

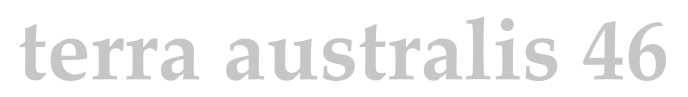


Textbox 6.1 Alphanumeric code for roads, drains and blocks Philip Hughes and Jack Golson

The four east-west roads were designated E-W Rd 1 to 4 from south to north and the four north-south roads N-S Rd 1 to 4 from west to east (Fig. 6.4). The main 4.5 ha blocks were labelled A to E from south to north and 2 to 12 from west to east, i.e. from A2 in the southwest corner of the station to E12 in the northeast corner (Figs 6.4 and 6.14)

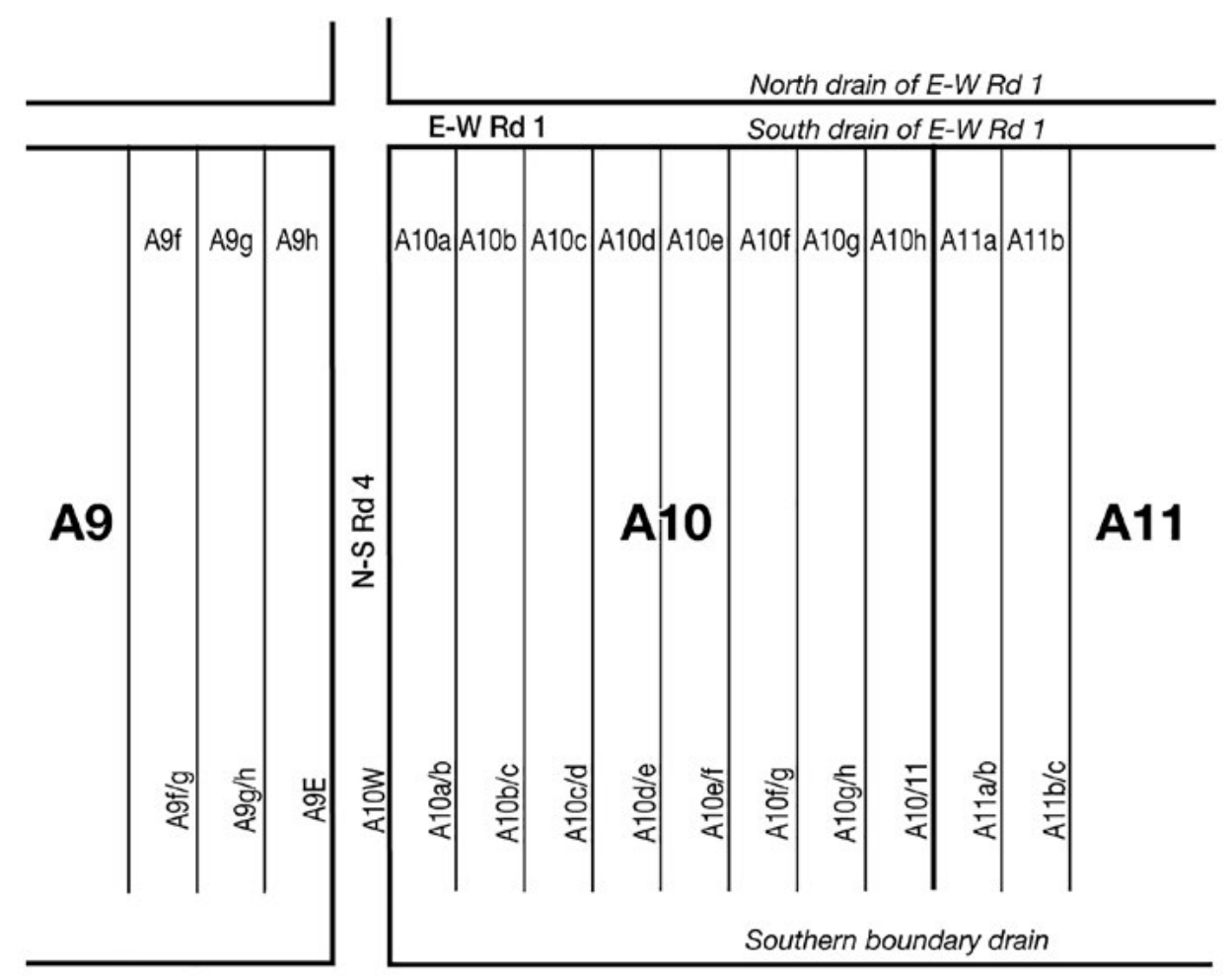

Figure 6.T1.1 The alphanumeric code illustrated.

Source: Drawing by Harrison Pitts.

Within each of the main 4.5 ha blocks (block $A 10$ is the example illustrated here) the eight sub-blocks were labelled a to $\mathrm{h}$ from west to east, i.e. A10a to A10h. The north-south drain between two main blocks, in our example blocks A10 and A11, was labelled A10/11. The minor north-south drain between two sub-blocks, A10b and A10c for example, was labelled A10b/c, and that between A11a and A11b, A11a/b.

The drains flanking the east-west roads, in our example E-W Rd 1, were referred to as the north drain and south drain of E-W Rd 1. Those flanking the north-south roads, in our example N-S Rd 4, were referred to, in the case of the eastern drain, as A10W (i.e. the western boundary of block A10) and for the western drain as A9E (i.e. the eastern boundary of block A9). 
McGrigor's plan for development within the boundaries of the Station aimed to combine adequate drainage of the property with a grid of access roads that provided individual blocks as uniform in size as possible (Fig. 6.15). Figures 6.4 and 6.14 indicate the alphanumeric code by which the Station management identified roads, drains and main blocks throughout the property (see also Textbox 6.1). Four east-west roads with flanking drains, built at $265 \mathrm{~m}$ intervals, supplied the framework of the scheme. The roads and their two associated drains were $15 \mathrm{~m}$ wide, which left strips $250 \mathrm{~m}$ wide between them for cultivation. North-south drains subdivided these strips into 4.5 ha blocks $(250 \mathrm{~m} \mathrm{x} 180 \mathrm{~m})$, with north-south roads and flanking drains at intervals between them. Minor north-south drains, spaced at $22.5 \mathrm{~m}, 45 \mathrm{~m}$ or $90 \mathrm{~m}$, allowed further subdivision according to the drainage requirements of each location. All drains were dug by hand (Fig. 6.16).

The Station code was adopted and extended by the members of the archaeological research team in the course of their work, which took place east of N-S Rd 3 and operated there in terms of the Station drainage plan (Fig. 6.14). An example is block A9, where archaeological work started in 1972. Figure 6.6 is an aerial view over part of this block, looking northeast from village land in the foreground and across the southern boundary drain complex of the Station, which forms the southern boundary of the block. Its northern boundary is the southern drain of the tree-lined E-W Rd 1 in the upper-left corner of the picture, while its eastern boundary is the western drain of N-S Rd 4, which is under construction in the centre top. This western drain we called A9E because it formed the eastern boundary of A9 and on the same principle we called the other drain of N-S Rd 4, $25 \mathrm{~m}$ to the east, A10W, because it formed the western boundary of the yet undrained block A10.

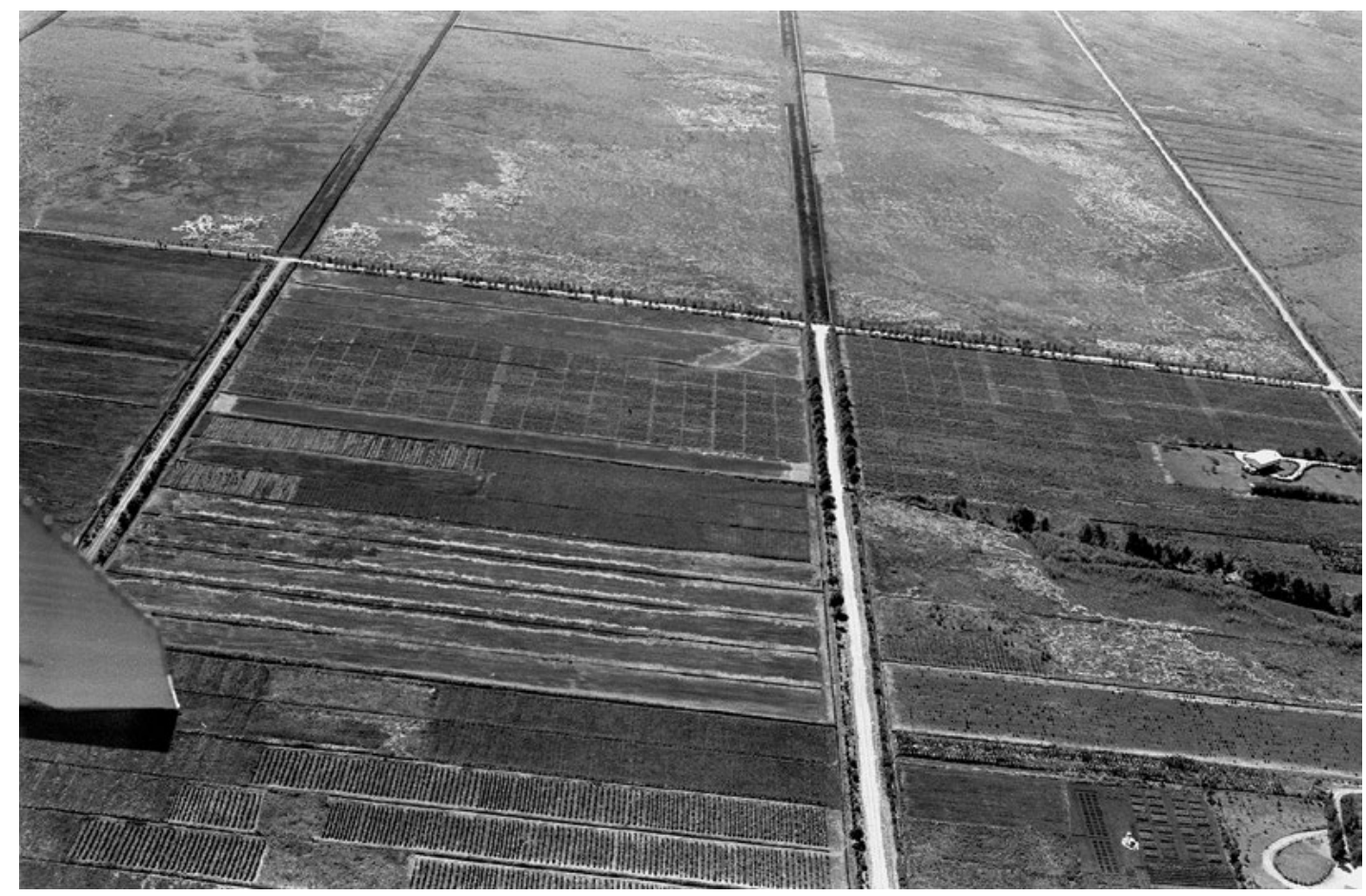

Figure 6.15 Developing the Station drain and road network east of N-S Rd 3, which runs across the middle of the picture.

These infrastructural developments were undertaken in 1972 solely to enable archaeological investigations in the eastern half of the property. All drainage for archaeological purposes was done in accordance with the Station drain and road plan. The first drains dug for the archaeology team, in block A9 in late June and July 1972 appear at the top right of the photograph. For a closer view see Fig. 6.6.

Source: Photograph by Wal Ambrose, Kuk archive, 1972. 


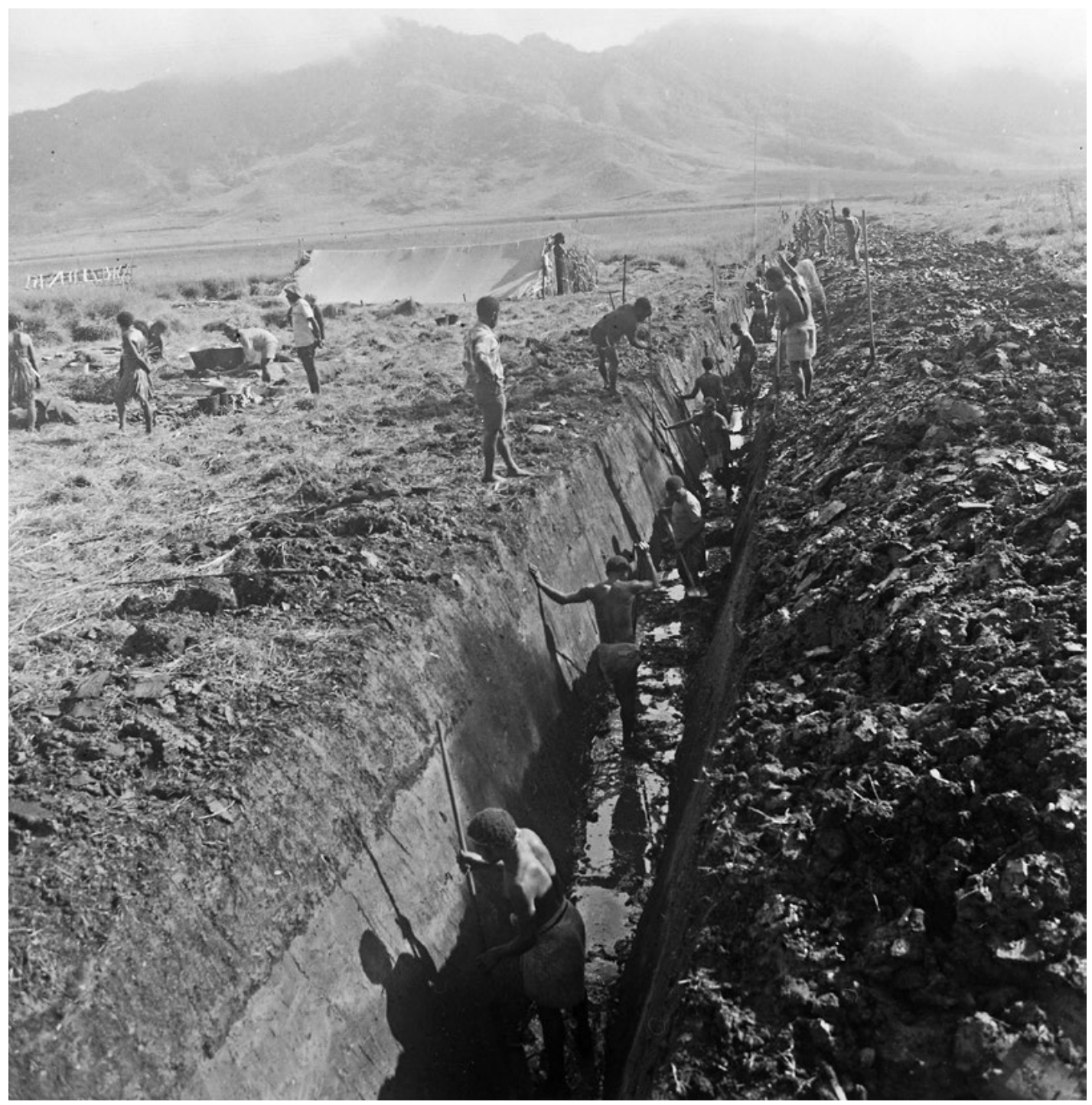

Figure 6.16 Digging the eastern boundary drain of Kuk Station in the course of the development of the drain and road network shown in Figure 6.1.

Source: Photograph by Wal Ambrose, Kuk archive, 1972.

Figure 6.6 shows five of the seven minor N-S drains dug by workmen at $22.5 \mathrm{~m}$ intervals to remove water from the block north to the E-W Rd 1 southern drain. The eight strips into which block A9 was thus subdivided were called A9a to A9h from west to east and the minor drains responsible for the subdivision became $\mathrm{A} 9 \mathrm{a} / \mathrm{b}$ to $\mathrm{A} 9 \mathrm{~g} / \mathrm{h}$. The western boundary of the block was a larger $\mathrm{N}-\mathrm{S}$ drain separating it from block $\mathrm{A} 8$ and known as drain A8/9. Like the minor internal drains of A9, the block-dividing drain A8/9 was connected to the southern drain of E-W Rd 1 to the north and stopped short of the southern boundary drain.

In the ways described above, block A9 is typical of all the blocks east of N-S Rd 3 and south of E-W Rd 4, just south of which the swamp surface reaches its lowest point after its gentle but continuous fall from the southern boundary. To the north of this, in the E blocks, there is a marked rise of ground surface at the foot of Ep Ridge (Fig. 6.8) so that all N-S drains fed south into the north drain of E-W Rd 4. 


\section{Formation processes and swamp deposits}

We describe the character of the deposits and present an account of their depositional history and the post-depositional changes (cultivation, bioturbation and soil-formation processes) to which they have been subjected. In addition to field descriptions, a wide range of laboratory methods has been used to characterise and interpret these deposits, including thin section description (Textbox 6.2) and X-radiography (Textbox 6.3).

Three major types of sediment comprise the swamp deposits at Kuk: alluvial deposition of sediments eroded from the catchment, aeolian deposition of airfall tephras and on-the-spot formation and deposition of organic material during lacustrine periods and in abandoned channels. Basal red-brown highly organic swamp deposits several metres thick formed during the Pleistocene before the Last Glacial Maximum (LGM), which peaked at about 21,000 years ago (Reeves et al. 2013). These are capped by formations up to $1.8 \mathrm{~m}$ thick consisting of black to grey organic and inorganic clays and garden soils, which represent alluvial deposition and soil formation since the start of the LGM. Tephra deposition has occurred episodically throughout the Pleistocene and Holocene.

These different types of alluvial, organic and volcanic accumulation have been subject to periodic soil-formation processes that are largely determined by drainage. Soil formation (pedogenesis) occurs in freely drained portions of the stratigraphy and ceases, or is severely retarded, within saturated portions. Soil formation comprises biological, chemical and physical processes, including (Dent, Browning and Rogaar 1976; Collins and Lavney 1983):

- bioturbation, or mixing, of free-draining portions of the sediment profile by faunalturbation, e.g. by earthworms, termites, ants and other soil fauna (Paton, Humphries and Mitchell 1995: 33-68), and floralturbation, e.g. root activity;

- chemical weathering of primary (pyroclastic) and secondary (clay) minerals, with increasing alteration through time; and,

- dewatering and aeration following initial drainage of organic sediments, with subsequent compaction, decomposition and oxidation of organic matter and resultant wastage and subsidence of the deposit (Burton and Hodgson 1987: 22-24).

The nature of soil-formation processes at Kuk has varied greatly, spatially and through time. The 'higher ground', comprising the tephra-mantled land surface predating 50,000 years ago, has always been well drained and exhibits highly weathered soils that have been subject to prolonged pedogenesis. By contrast, areas of the swamp exhibit variable pedogenesis depending primarily on the extent and duration of prehistoric drainage, as well as variability in watertables along the 'swamp margin' in response to changes in climate.

\section{Textbox 6.2 Thin section description}

\section{Tim Denham}

The description of soil and sediment thin sections, termed micromorphology, is a sedimentological technique widely used by archaeologists to augment their understanding of deposits at agricultural and habitation sites (Courty, Goldberg and MacPhail 1989).

Thin section analysis is usually employed on undisturbed samples collected from archaeological sites, namely samples that are collected in the field using special sampling tins (called Kubiena or Brewer tins) for impregnation with resin in the laboratory. Thin sections, each comprising a 25-30 $\mu \mathrm{m}$ thick slice of sediment mounted on a glass slide, are prepared from the impregnated block, examined under a microscope and described using standard terminology (Bullock et al. 1985; Stoops 2003).

\section{terra australis 46}


At Kuk, the technique was applied selectively to provide high-resolution interpretations of Phase 1, 2 and 3 palaeosols (literally 'old soils'), feature fills and stratigraphic units (Fig. 6.T2.1). The technique provided a means to understand how deposits formed, and particularly to identify soil characteristics associated with past human activities on the wetland and past hydrological conditions, which are a major determinant of soil formation processes.

Thin section description at Kuk enabled:

- primary and secondary attributes of deposits to be differentiated, namely those attributes associated with initial formation as distinct from those acquired following formation and burial;

- pedofeatures, essentially microscopically visible features within the soil, to be interpreted with respect to soil formation processes and past human activities on the wetland; and

- the processes involved in the formation of minor and major stratigraphic units to be clarified.

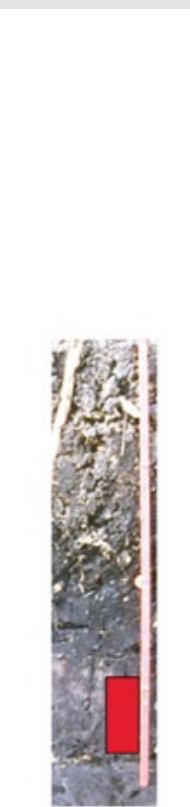

(a)

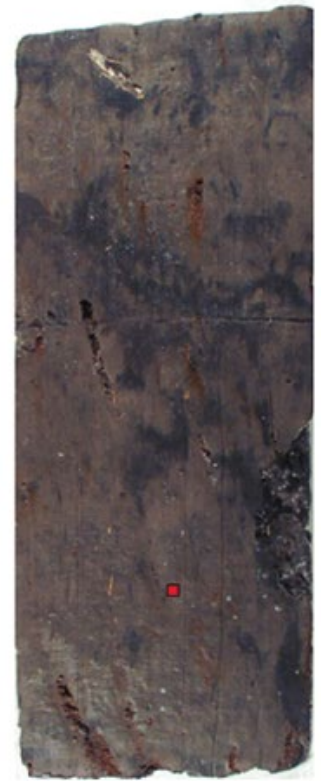

(b)

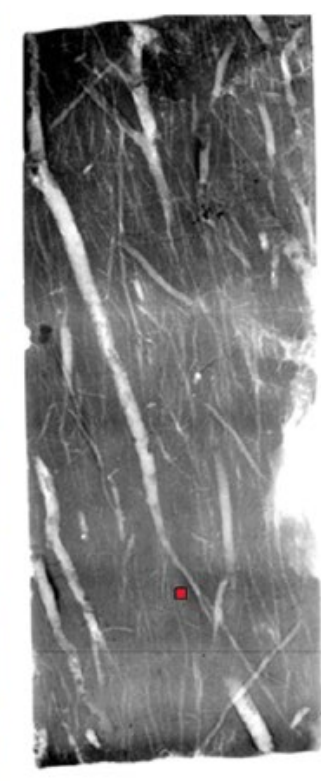

(c)

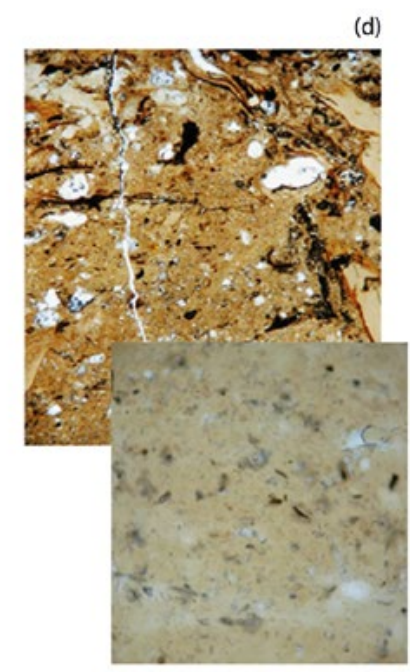

(e)

Figure 6.T2.1 From field description to thin section description: linking macro-, meso- and microlevels of stratigraphic analysis.

(a) Field photograph of stratigraphic column from surface to base of grey clay. The area in red shows the location of a sampling tin. See main chapter for description of the stratigraphic column. (b) Photograph of the grey clay sediment column within a sampling tin. Note the marbling effect of grey and black clays and ferric staining along recent voids. The area in red shows the location of (d). (c) X-radiograph of the same grey clay sediment column photographed in (b). Note the clear depiction of vertically oriented channels (curvilinear voids caused by roots and soil mesofauna). The lighter and darker banding across the image is caused by fluctuations in sample thickness. The area in red shows the location of (d). (d) Photomicrograph of pedofeatures within grey clay (image width of c. $2.5 \mathrm{~mm}$ ). Pedofeatures include voids filled with downward percolated clay, or argillans, along the right-hand side of the image and ferric staining around the edges of filled voids. Recent voids are unfilled white areas in the image. (e) More detailed photomicrograph of grey clay comprising a fine fraction of dusty to impure clay and a coarse fraction of phytoliths and microcharcoal fragments (image width of c. $0.6 \mathrm{~mm}$ ).

Source: Photographs (a)-(b) and photomicrographs (d)-(e) by Tim Denham, $X$-radiograph (c) by Alain Pierret. 


\section{Textbox 6.3 X-radiography Alain Pierret and Tim Denham}

Radiography refers to imaging techniques in which a penetrating radiation is used to produce an image of the internal structure of materials. The use of $X$-radiography in geology and soil sciences was introduced by Hamblin (1962) and Krinitzsky (1970), who showed that 'thick bedded' or 'massive' sedimentary deposits really contain many complex primary structures that are visible with $X$-rays but are otherwise poorly expressed or invisible (Krinitzsky 1970: 47). Typically, such structures correspond to variations in porosity, chemical/mineral composition and water content.

Practically, a thin slab of soil (c. $20 \mathrm{~mm}$ thick) extracted from an undisturbed monolith collected in the field is positioned in front of an image detector (e.g. photographic film) and exposed to the beam of an $X$-ray tube. X-radiography's main limitation is that it is restricted to soil types from which $10-20 \mathrm{~mm}$ thick slices can be conventionally extracted, i.e. soils with sufficient cohesion and few coarse elements such as gravel. Special care must be taken to ensure that soil slabs are uniformly thick because variations in thickness show up in the images. Provided access to an existing facility is granted, $\mathrm{X}$-radiography is inexpensive. If required, output images can be quantified by means of image analysis (e.g. Pierret and Moran 1996). The principal advantage of the technique is that it provides virtually immediate insight into soil arrangement at the meso-scale (i.e. resolution of features 0.1 to $1 \mathrm{~mm}$ in size, depending upon the imaging system used) without the need for complex sample preparation. The meso-scale investigation of soil and sediment characteristics using X-radiography provides the essential, though often missing, link between macroscale field descriptions and detailed micromorphological studies, i.e. thin section analysis.
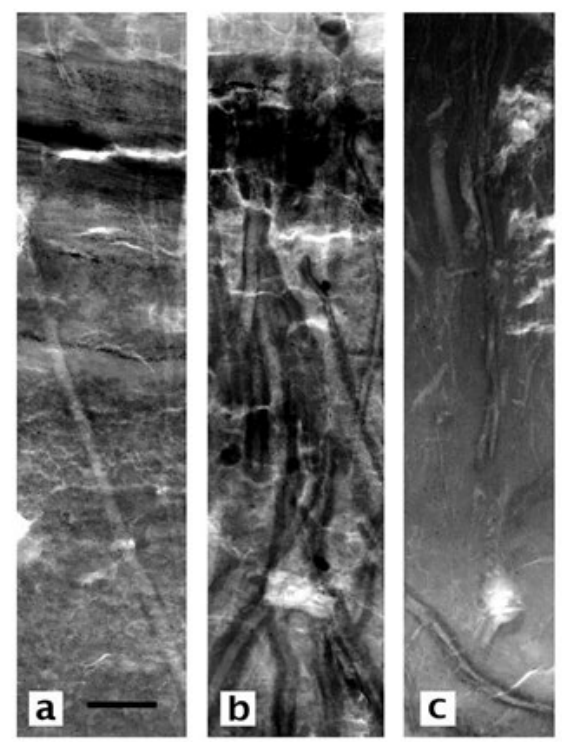

Recently, X-radiography has been used on archaeological sediments to detect soil structures and pedoturbation, to reveal tephra lenses within peats and to assess rapidly primary and secondary attributes of deposits prior to subsequent analysis (Barham 1995). At Kuk Swamp, Denham (2003a) used X-radiography to detect former palaeosols and assess the degree of pedogenic homogenisation within a sample (Fig. 6.T3.1). The differentiation of deposits that retain their original stratification, as opposed to those that were subject to extensive post-depositional pedogenic modification, has proven essential for choosing samples for subsequent analysis, understanding site formation processes and interpreting analytical results (Denham 2003a; Denham, Sniderman et al. 2009).

Figure 6.T3.1 X-ray absorption images of samples from Kuk.

Showing: (a) a high degree of preservation of stratification within a palaeochannel fill with only a few recent vertically oriented channels (light, rectilinear areas); (b) intense bioturbation of preexisting stratification with redistribution of material from the dark layer at the top of the image along channels; and (c) well homogenised stratigraphic unit with superimposed channels (lighter areas) representing recent root and faunal activity. Black horizontal line in (a) represents $10 \mathrm{~mm}$.

Source: $\mathrm{X}$-radiographs by Alain Pierret. 


\section{Red-brown swamp deposits}

The basal swamp consists of red-brown highly organic swamp deposits (commonly 40 per cent or more organic matter), predominantly organic muds with variable amounts of original fibrous organic matter and wood. There are numerous exposures of thin tephras, including one that seems to occur at or within a few millimetres of the top of the red-brown unit (Fig. 6.17). In the field this was called 'Ep-4', originally meaning the fourth tephra below Ep Tephra (see Table 7.1). The surface of the basal swamp is nearly horizontal. It falls about $0.4 \mathrm{~m}$ from the southern end of blocks A10 and A11 to the northern end of these blocks and only another $0.4 \mathrm{~m}$ to the lowest part of the swamp in the D blocks, a total distance of about $1 \mathrm{~km}$. The surface of this unit then rises about $0.4 \mathrm{~m}$ in the $\mathrm{E}$ blocks, where it is covered by at least $2.5 \mathrm{~m}$ of fan deposits from Ep Ridge.

The red-brown colour of the deposits throughout the swamp, the generally good preservation of plant remains (including wood) and the widespread presence of thin horizontal bands of tephra show that the deposits formed under swampy or lacustrine conditions and have remained permanently saturated and relatively undisturbed since they accumulated. Timber was uncovered during the digging of Station drains, in the form of roots, fallen logs and occasional stumps apparently in growth position. It proved to be from trees prominent in the upper reaches of the lower montane forest like beech (Nothofagus) and conifers (see Chapter 9), indicating that at least in the later stages of red-brown swamp accumulation climatic conditions were generally colder than today.

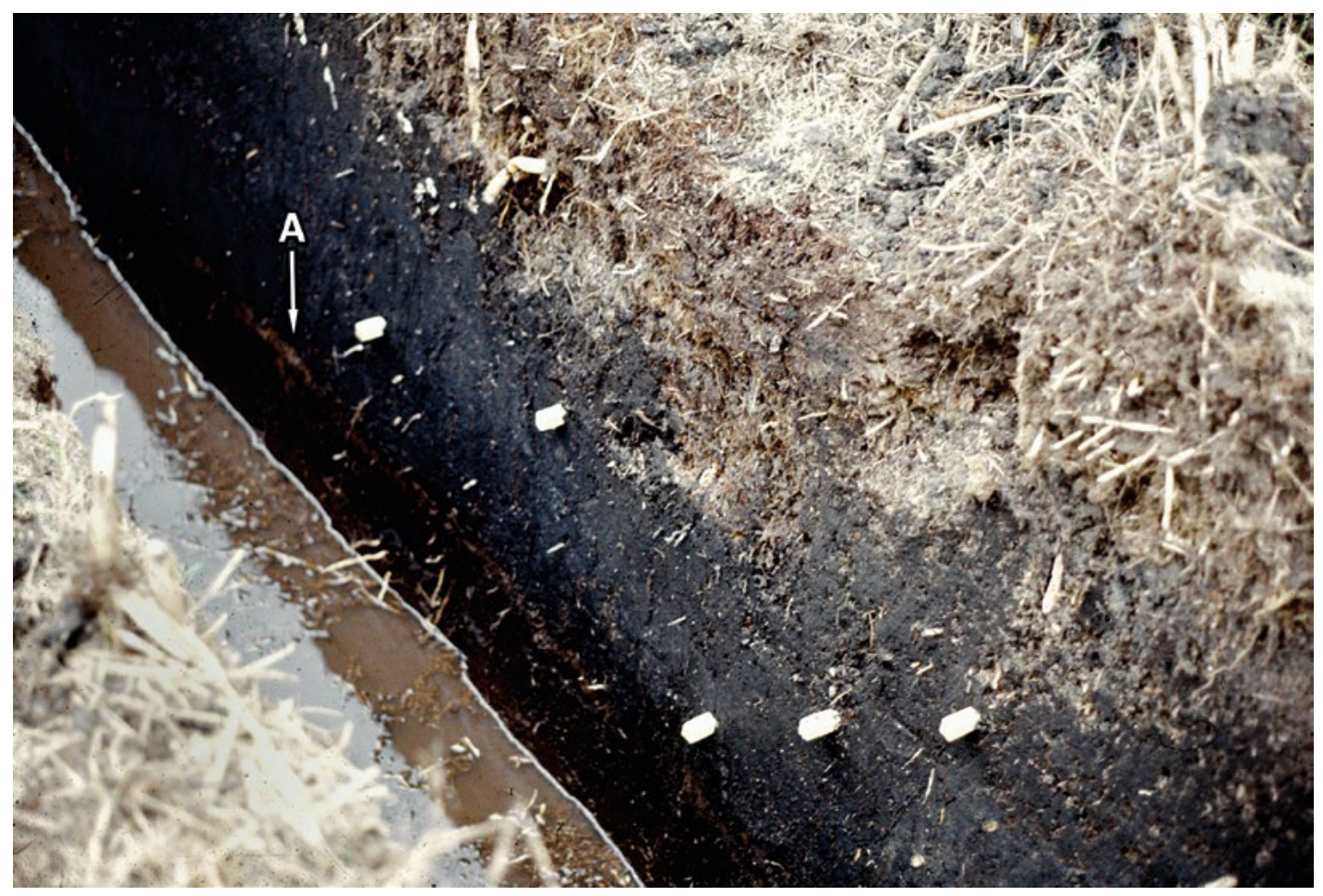

Figure 6.17 The organic/inorganic transition in the swamp stratigraphy shown in the west wall of drain $\mathrm{D} 7 \mathrm{f} / \mathrm{g}$ in the lowest part of the swamp.

Notes: a) the tephra called Ep-4 (arrow A) at the transition between the underlying red-brown swamp deposit and the overlying black organic clay; b) the grey clay that is so prominent a feature of the swamp stratigraphy to the south (see Figs 6.18 and 6.19) is here barely discernible in this low part of the swamp; and c) the pegged feature is a Phase 5 field ditch.

Source: Photograph by Philip Hughes, Kuk archive, 1975. 
The swamp probably began accumulating more than 50,000 years ago. About 35,000 years ago, there was an abrupt change from red-brown swamp mud to black organic clay that was referred to in the field as the organic/inorganic transition. These ages are based on an evaluation of radiocarbon dates from relevant levels of the stratigraphy, in which dates on charcoal and wood were favoured over those on materials of organically more complex origins (see Appendix 6.1).

\section{Clay deposits}

\section{Black organic clay and black to dark grey slightly organic clay}

The organic/inorganic transition is a change that for the most part took place over a few millimetres. The lie of what appeared to be the same tephra (Ep-4), at or just below the stratigraphic change, suggested that this occurred at the same time across the swamp.

In the southeastern part of the swamp, the black organic clay is on average $170 \mathrm{~mm}$ thick and has a mean organic matter content of 22 per cent. It grades upwards over the space of a few millimetres into a black to dark grey slightly organic clay. This unit is increasingly lighter in colour and less organic upwards. Its average thickness is $150 \mathrm{~mm}$ and mean organic matter content 11 per cent. Two major tephras occur in this unit, Rom (10-20 mm thick) at or near its base and Ep (20-50 mm thick) towards its top (see Appendix 6.1 and cf. Tables 7.1 and 7.2).

In contrast to the underlying red-brown swamp deposits, the two later units contain few if any macroscopic plant materials like sedges and grasses or the leaves and seeds of trees growing at the time they were laid down. Pieces of wood are also very uncommon. It appears that plant remains decayed rapidly due to oxidation, presumably because of periodic drying out of the deposits as they accumulated. Both units are heavily penetrated by younger roots. The frequent presence of long exposures of Rom and especially Ep Tephras indicates that deposition probably occurred in standing water and that the sediments have undergone relatively little post-depositional disturbance, especially in their deeper levels.

The beginning of black organic clay deposition is part of the organic/inorganic transition, dating to around 35,000 years ago, as discussed in Appendix 6.1. The end of the black to dark grey slightly organic clay into which it grades is marked by the formation of a conspicuous grey clay starting around 10,000 years ago (Fig. 6.10C). Within this 25,000-year-long period, chronological markers are provided by Ep and Rom, though the dating of these tephras is imprecise (Table 7.2). A $150 \mathrm{~mm}$ diameter $\log 30 \mathrm{~mm}$ below Rom provides a maximum calibrated age of close to 25,000 years not only for the tephra but for the change from black organic clay to black to dark grey slightly organic clay which it straddles (Fig. 6.10B).

Hughes, Sullivan and Yok (1991: 233-234) have estimated that the accumulation of inorganic sediment in the two units under discussion represented an average erosion rate that lowered the ground surface in the southern catchment $1.5 \mathrm{~mm}$ per 1000 years or removed 1.2 tonnes of soil/ $\mathrm{km}^{2} / \mathrm{year}$. This is an extremely low rate and indicates that the catchment was very stable, probably under relatively undisturbed forest cover. The deposition of dark grey slightly organic clay ceased 10,000 years ago when Phase 1 of swamp use began (see Chapter 11).

\section{Grey clay}

The relatively short period of Phase 1 cultivation some 10,000 years ago was associated with the operation of a disposal channel, which in the field was called Kundil's Baret after one of the workmen; Tim Denham has subsequently called it channel 101 in his register of features. Hughes and Golson consider this to have been an artificial channel, whereas for Denham it is a natural feature (Denham, Golson and Hughes 2004: 269-274; see Chapter 11). When cultivation ceased, this channel was sealed with a distinctive grey clay (Figs 6.18-6.22), which also filled holes and 
basins resulting from plant management on the palaeosurface, as well as other depressions not necessarily artificial in origin. This grey clay was washed in from the catchments of the swamp and over the next 3000 years or so accumulated across it. The clay that derived from the southern catchment forms a subdued fan in which it is thicker $(-300 \mathrm{~mm})$, less organic $(-6$ per cent) and more dense $\left(-0.8\right.$ tonnes $\left./ \mathrm{m}^{3}\right)$ at the apex than along the distal margins $(-200 \mathrm{~mm}, \sim 10$ per cent and -0.65 tonnes $/ \mathrm{m}^{3}$ respectively). The fan-like nature of deposition is even more pronounced on the northern side of Kuk, where the thickness of grey clay washed in from the steep slopes of Ep Ridge decreases markedly over a few hundred metres, from up to $600 \mathrm{~mm}$ in the E blocks to less than $100 \mathrm{~mm}$ in the D blocks.

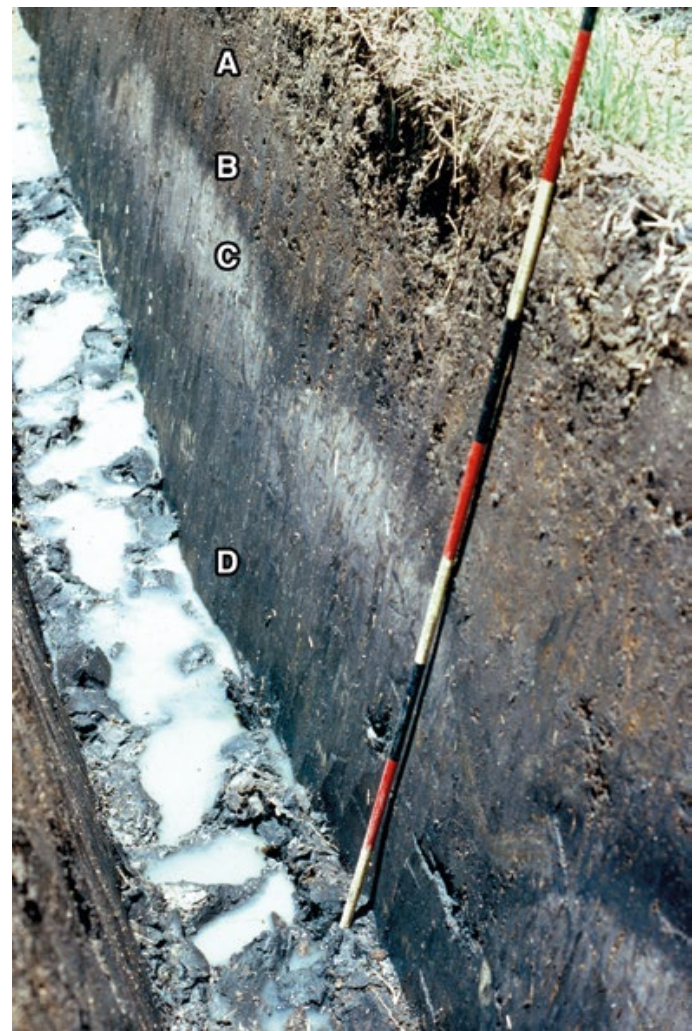

Figure 6.18 Stratigraphy looking SSW at the west wall of drain B10c/d, where the grey clay is conspicuous, midway between the lowest part of the swamp and the southern boundary drain.

The four stratigraphic elements of Figure 6.11 are depicted here for one of the B block drains: the grey clay $(C)$ is perched midway down the drain wall, with black clay $(B)$ and garden soil (A) above and black organic clay (D) below to the base of the drain. The surface of grey clay is penetrated by a minor Phase 4 ditch to the left of the ranging pole and the layer is totally removed by a bigger Phase 4 ditch with Olgaboli (Q) Tephra to the right. The ranging pole is graduated at 200 $\mathrm{mm}$ intervals.

Source: Photograph by Sam Garrett-Jones, Kuk archive, 1974.

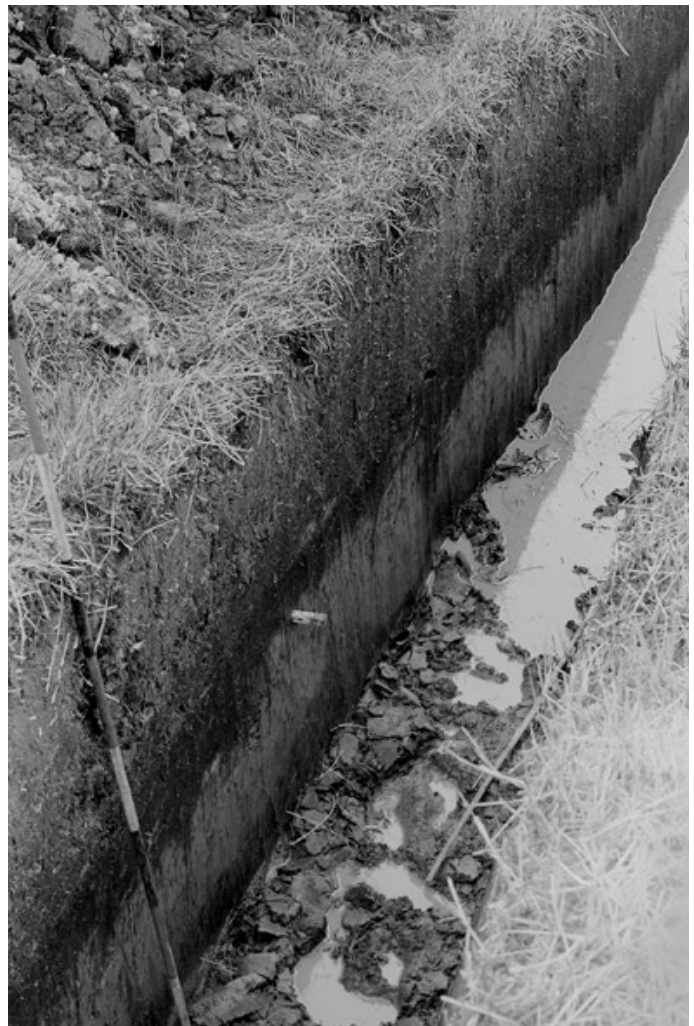

Figure 6.19 East wall of drain A11d/e in the area where grey clay is thickest, view to SSE.

In this A block drain the stratigraphic profile is almost totally made up of the upper three of the four major stratigraphic units, with garden soil and black clay above grey clay at the bottom of the drain wall and only the very top of the underlying black organic clay exposed at the base of the drain. The ranging pole is graduated at $200 \mathrm{~mm}$ intervals.

Source: Photograph by Barbara Greaves, Kuk archive, 1974. 


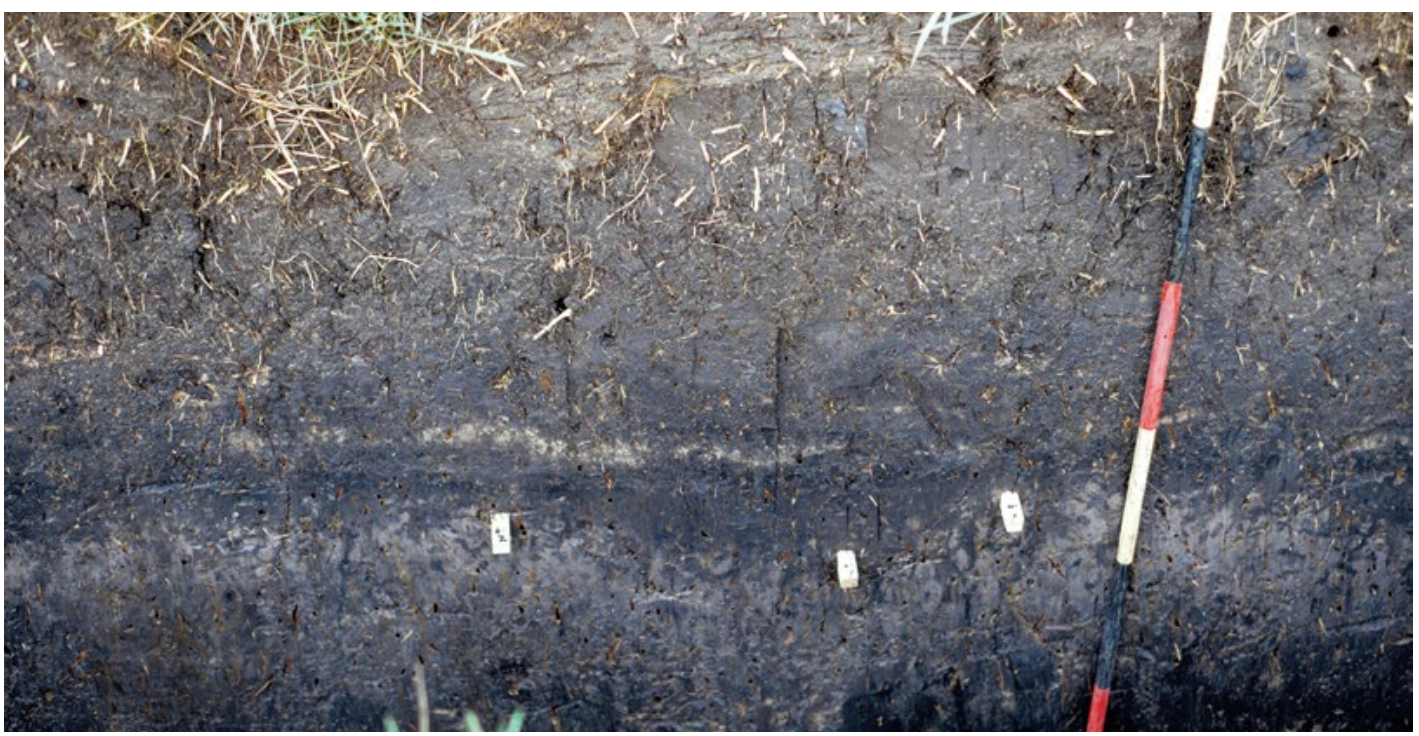

Figure 6.20 Looking at the west wall of drain B10e/f towards its southern end, where the black clay above grey clay thickens to fill a Phase 2 cultivation feature in the grey clay surface.

The distinctive lens that sits on the black clay surface above and outside the cultivation feature is Mun (Niupela or NP) tephra. The ranging pole is graduated at $200 \mathrm{~mm}$ intervals.

Source: Photograph by Philip Hughes, Kuk archive, 1974.

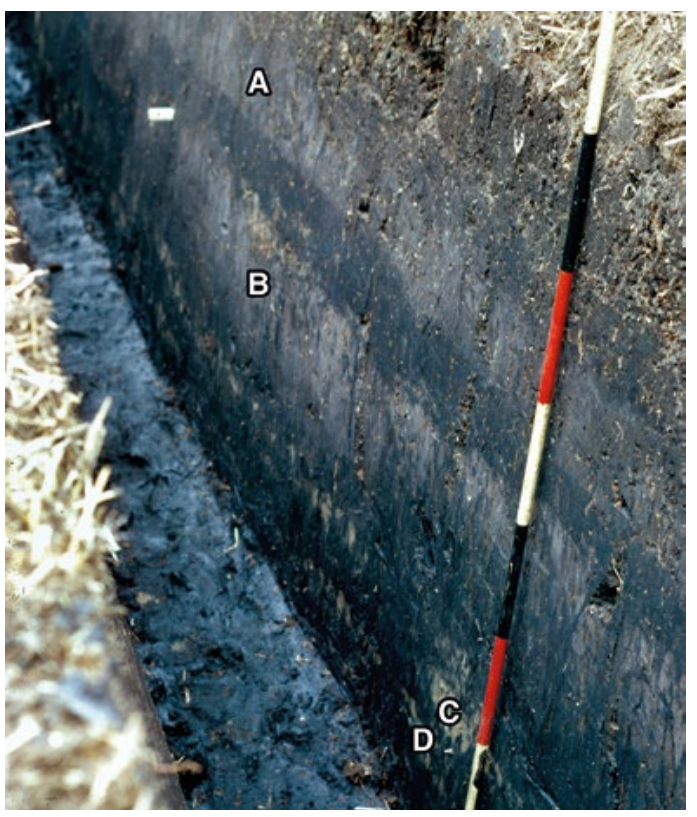

Figure 6.21 The place of 'new grey clay' (A) in the stratigraphy of drain $A 10 \mathrm{~g} / \mathrm{h}$ west wall looking SSW.

The 'red and white' material that we call Kuman fills a Phase 2 cultivation feature in the surface of grey clay (B) and there are discontinuous lenses of Ep (C) and Rom (D) tephras in the black organic clay at the base of the drain. The ranging pole is graduated at $200 \mathrm{~mm}$ intervals.

Source: Photograph by Philip Hughes, Kuk archive, 1974.

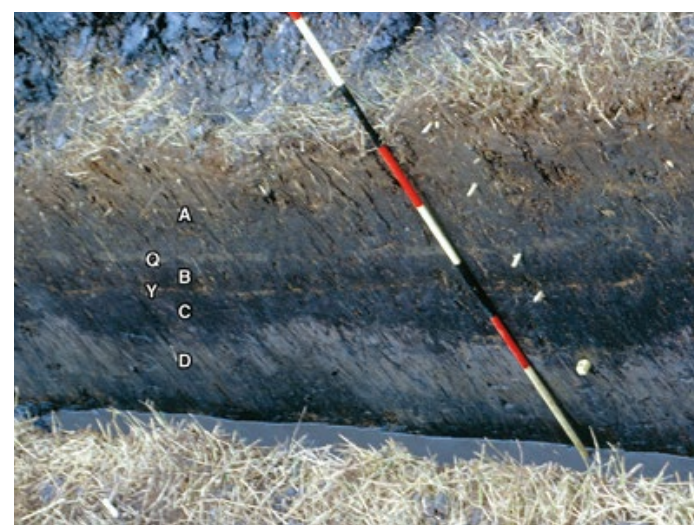

Figure 6.22 Looking WSW at the stratigraphy of the west wall of drain A11a/b, showing the garden soil (A) above the black clay (C) and the grey clay (D) underneath.

A striking feature here and elsewhere in the northern $60 \mathrm{~m}$ of the drain is the extended presence of Olgaboli (Q) Tephra and Baglaga (Y) tephra in the stratigraphy, the former stretching between the pegs at the left and the right margins of the image. The level of the latter, c. $100 \mathrm{~mm}$ below Olgaboli, is marked by the second lowest peg in the column to the right of the ranging pole. Baglaga tephra sits almost immediately above the top of black clay $(C)$ and Olgaboli in the garden soils (A). Between them is an 'intermediate' horizon (B) that is believed to mark the beginning of soil tillage at the site. The ranging pole is graduated at $200 \mathrm{~mm}$ intervals.

Source: Photograph by Jim Rhoads, Kuk archive, 1973. 
From the outset, Golson and Hughes (1980; also Hughes, Sullivan and Yok 1991) interpreted the grey clay as the product of accelerated erosion in the dryland caused by forest clearance for cultivation. This interpretation has been confirmed by the work of Haberle and others (see Chapter 11, section 'Landuse'; cf. Wilson 1985: 96-97). Hughes, Sullivan and Yok (1991: 233-234) have estimated that the accumulation of grey clay derived from the southern catchment represented an average erosion rate that lowered the landscape $12 \mathrm{~mm}$ per 1000 years or removed 10 tonnes of soil $/ \mathrm{km}^{2} /$ year. Although this was almost a tenfold increase in the average erosion rate over that of the preceding 20,000 years, it nevertheless was comparatively low for humanly impacted landscapes in the tropics (Hughes, Sullivan and Yok 1991: 235-237). Deposition of the grey clay ceased about 7000 years ago when Phase 2 use of the swamp began (see Chapter 12).

\section{Black clay}

The black clay accumulated during and after the operation of Phases 2 and 3 in the swamp between 7000 and 2500 years ago, the latter being an estimate of the age of Mun or Niupela (NP) ash, which marks the end of black clay deposition (Fig. 6.10E; cf. Fig. 6.20). The clay was derived from ongoing soil erosion in the surrounding landscape and it is likely that much of this material was intercepted and carried beyond the limits of the swamp when the various disposal channels servicing Phases 2 and 3 were operating.

The black clay, which is on average $100 \mathrm{~mm}$ thick, has the same consistency as the grey clay. Surprisingly, it is low in organic matter $(<10$ per cent), iron and manganese, all of which could have accounted for the dark colour. We think that organic matter in the form of decomposed organic soil material and finely divided charcoal, perhaps derived from gardening, has 'stained' and bonded with poorly ordered clay minerals to give the black colour.

The upper fills of the Phase 3 channels in the southeastern part of the Station are also usually black clay, but in some situations lenses of grey clay occur within it. In a few cases, these grey clay lenses extend for a few metres to tens of metres beyond the banks of channels. These localised occurrences of younger grey clay are referred to as 'new grey clay' (Fig. 6.21). They were probably deposited in floodwaters particularly rich in sediment derived from erosion of the tephra-covered hills in the southern catchment.

The sharpness of the break between the black clay and the underlying and overlying units, together with the relatively frequent occurrence of the formation known as Komun (Red and White, $\mathrm{R}+\mathrm{W}$ ) in the base of Phase 2 basins and of $\operatorname{Kim}(\mathrm{R})$ tephra in the stratigraphy above them, indicate that the black clay has not undergone major post-depositional disturbance. (For the status of Komun see Chapter 7, section 'Field investigations of volcanic ash at Kuk'.)

\section{Garden soils}

The deposits that accumulated from about 2500 years ago, after the abandonment of Phase 3, were collectively referred to in the field as 'crumby black' because they contained clearly distinguishable soil aggregates that were absent from the underlying clay sediments. For simplicity, the 'crumby black' came to be called 'garden soil' for reasons discussed below (Fig. 6.22). These garden soils average about $300 \mathrm{~mm}$ thick and on the southern side of the swamp they thicken to about $350 \mathrm{~mm}$ towards the southern catchment, which was the major source of sediment from which they were formed.

The first unit of the garden soil, immediately overlying the black clay, is a soft silty clay that contains fine soil aggregates. This highly distinctive formation grades upwards into firmer clayey material characterised by coarser soil aggregates to about the level of Olgaboli (Q) Tephra where this is present. Where Baglaga $(\mathrm{Y})$ tephra occurs in the profile, it is the finely textured component 
of the soil that separates it from the black clay lying a few millimetres below. The last Phase 3 ditches to be abandoned have this soil as a prominent element of their fill, with Baglaga tephra dipping deeply into them (see Fig. 13.9).

Hughes and Golson consider that the consistent lie of this finely textured material in relation to the black clay, Baglaga $(\mathrm{Y})$ tephra and the late Phase 3 ditches whose upper fill it forms, together with the very sharp nature of the contact between it and the underlying black clay, demonstrates that the abrupt change from clay to soil aggregates was depositional in origin and not the result of post-depositional soil formation. Golson and Hughes (e.g. Golson 1977a: 621-622) have attributed this change to the onset of a new practice in dryland cultivation, namely soil tillage, with a consequent change in the character of the erosional products washing into the swamp, from clay to a more silty clay deposit that contains soil aggregates (see Chapter 14, section 'Soil tillage as an innovation').

In contrast, Denham (2003a: 282-283) considers the unit to result from soil formation on slowly accumulating sediments. Soil formation was sufficient to develop aggregates within recently deposited alluvium, but it was insufficient for deeper bioturbation to remove traces of the Baglaga $(\mathrm{Y})$ tephra band within the stratigraphy as a whole. Similar types of aggregates within abandoned ditches are likely to result from a combination of erosion of adjacent land surfaces and soil formation.

The garden soil above the finely textured soil discussed above consists of undifferentiated dark brownish clayey sediment with large soil aggregates. At its base there would have been an input of coarser-textured soil from the digging of the field ditches of Phase 4. Most of it, however, resulted from the making of raised garden beds with the spoil from the grid of garden ditches dug during Phases 5 and 6 of the agricultural sequence. Despite disturbance by intensive root penetration and the burrowing of small invertebrate animals such as beetles, lenses of Olgaboli (Q) (between about 1250 and 950 years old; see Fig. 6.10F) and especially Tibito (Z) (about 350 years old; see Fig. 6.10G) commonly survive because they were covered over by raised garden beds, and protected from being disturbed. Tibito Tephra is always above Olgaboli, which in turn is always above Baglaga. This demonstrates that despite considerable post-depositional disturbance, evidence for progressive net accumulation of sediment across the swamp between phases has survived in these garden soils.

\section{Surface layers}

As we saw at the beginning of the section about Kuk Swamp and its drainage, much of the surface was peat-like material formed by roots and other plant remains. Often this would not support the weight of men laying out survey lines and they had to swim or use a boat because any firm 'bottom' was too deep. In such areas, the surface consisted of floating mats of vegetation separated by water from the firm 'bottom' formed by the garden soil of the swamp stratigraphy.

As it was drained, the swamp underwent rapid shrinkage due to drying, oxidation, compaction and the loss of the buoyancy effect of the groundwater (McGrigor 1973: 34-39). In a trial area in the B blocks, McGrigor found there was an average shrinkage of 2 feet (about $0.65 \mathrm{~m}$ ) in the first three months following drainage. Most of this shrinkage would have occurred in the soft surface peat-like material. By the time the first archaeological and geomorphological investigations were carried out in the 1970s, this drained surface 'peat' was already rapidly degrading and was seldom more than $200 \mathrm{~mm}$ thick. Normally, this modern peat consisted of two components, an underlying very soft, highly organic clay (referred to in the field as 'greasy black') and an overlying horizontally bedded layer of compacted fibrous plant material, mainly roots (referred to as 'felted peat') (Fig. 6.23). In some places, only one or the other of these two components was present and in others neither. The 'greasy black' is sapric peat, i.e. humified plant material derived from the decay of the overlying fibrous or 'felted' peat. 


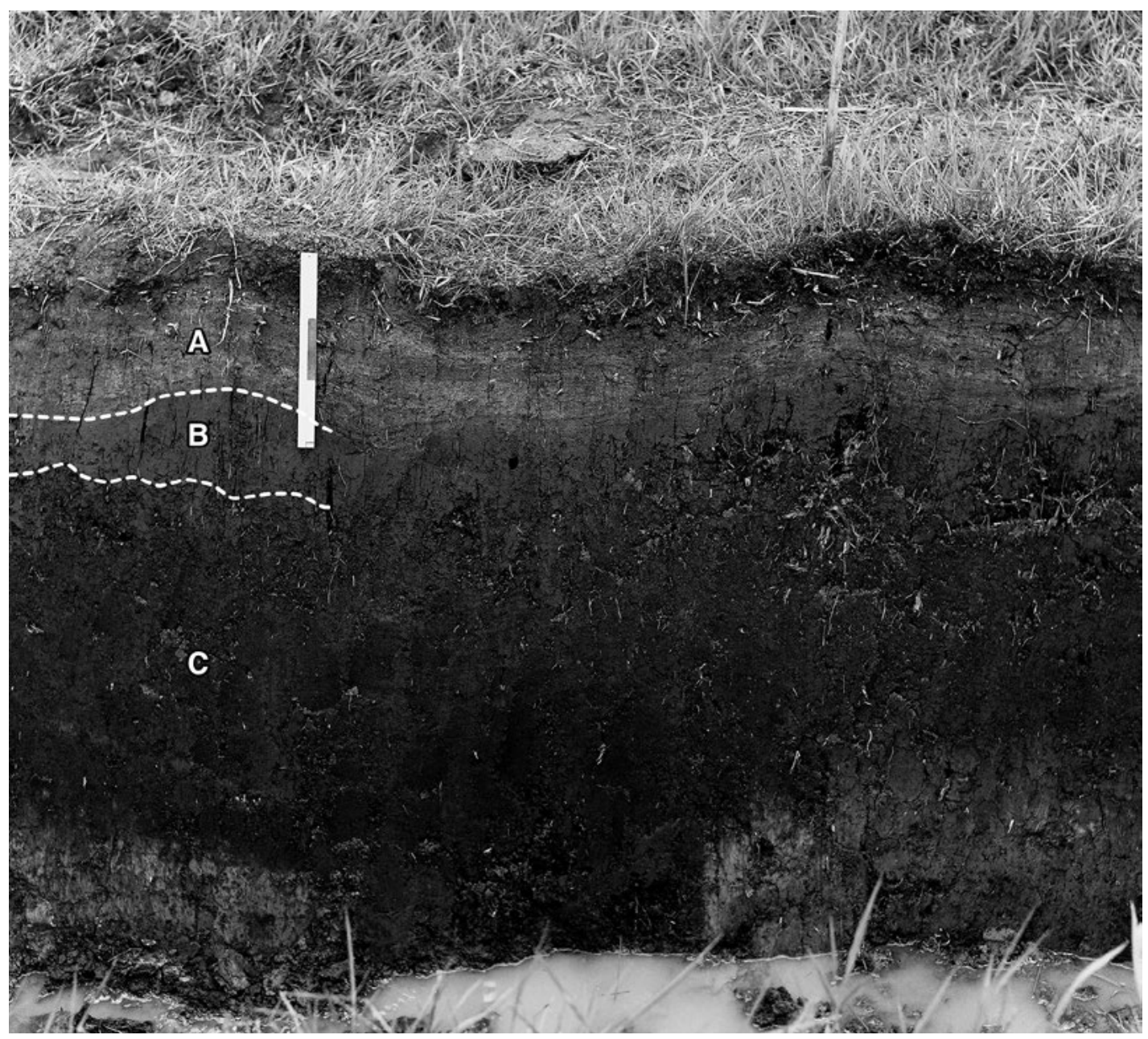

Figure 6.23 The surface layers (A and B) on drain A9E, west wall, cap garden soil $(C)$ and seal in a Phase 6 ditch. The two components, which can be clearly distinguished, are 'felted peat' (A) and 'greasy black' (B). The scale is graduated at $100 \mathrm{~mm}$ intervals.

Source: Photograph by Wal Ambrose, Kuk archive, 1972.

\section{Summary}

The Pleistocene red-brown organic swamp deposits older than 35,000 years at Kuk accumulated in a ponded area abutting the debris avalanche deposits from Mt Hagen and the slopes of Ep Ridge, where they have remained waterlogged since they were formed and unaltered to any significant degree by soil-forming processes. The interpretation of the post-LGM organic clay sediments laid down before cultivation of the swamp began 10,000 years ago is more complicated. Although these too were probably deposited in standing water and have undergone relatively little post-depositional disturbance, most of the plant remains associated with them appear to have decayed rapidly due to oxidation, presumably because of periodic drying out of the deposits as they accumulated. One possible reason for this change to periodic drying and oxidation is that by 35,000 years ago the ponded Kuk basin had largely filled with sediment and become more freely drained. Alternatively, or additionally, streams like the Guga, into which the swamp drained, may well have become entrenched by this time, leading to conditions of freer drainage. This latter explanation would better account for the abrupt change from the red-brown swamp to the overlying black organic clay. 
The characteristics of the deposits that accumulated after 10,000 years ago reflect the influence of changing landuse activities in the swamp and its catchments, as well as post-depositional processes associated with soil formation such as bioturbation and weathering. Between the relatively short phases of swamp cultivation described in subsequent chapters, sediment that washed in from the surrounding catchments accumulated under waterlogged conditions and remained relatively undisturbed, as evidenced by the widespread occurrence of stratified tephra layers and the preservation of the garden systems that they overlay. The grey clay deposited in the swamp between 10,000 and 7000 years ago is interpreted as the product of accelerated erosion in its dryland catchments caused by forest clearance for cultivation. The sediments that accumulated after 7000 years ago reflect erosion rates that were at least as high, if not higher, than in the preceding period (Hughes, Sullivan and Yok 1991: Table 2). By this time, the catchments would have been transformed into the open landscapes of garden, grassland and managed regrowth that are characteristic of the Wahgi Valley today. Present activities on the dryland such as gardening, ditching and pig-rooting, which can be seen to be contributing sediment to the streams that flow into the swamp today (Hughes, Sullivan and Yok 1991: 235), would similarly have been agents of erosion in the prehistoric past.

During periods of swamp cultivation, accumulation of sediments would have been interrupted because those coming in from the catchments would have been captured by the various waterdisposal channels used for drainage and carried out of the system. At the same time, drainage of those parts of the swamp being used for cultivation would have lowered the watertable. It was during these periods of cultivation that the deposits were subjected to the most intense postdepositional disturbance, particularly in Phases 5 and 6 from perhaps 750 to 100 years ago, when raised-bed gardening was practised (see Chapters 15 and 16).

\title{
Appendix 6.1: The Age of the Red-Brown Swamp Deposits and the Earliest Human Presence at Kuk
}

\author{
Philip Hughes and Jack Golson
}

\section{The age of the organic/inorganic transition as around 35,000 calendar years}

Six samples of organic mud were used to date the top of the organic swamp and three samples of the overlying black organic clay to date the beginning of this formation. The results are given in Table A6.1. They do not reveal a sufficient number of overlaps, even at two standard deviations ( $2 \mathrm{sd})$, to indicate the organic/inorganic transition as a time horizon at the site, as suggested in Chapter 6. As discussed below, they are, at the same time, much younger than dates on wood and charcoal from the equivalent levels. For these reasons the radiocarbon dates in Table A6.1 have not been calibrated.

By far the most striking difference from anything else in Table A6.1 is the date for the clay fines, fraction C, of sample ANU-1458 from immediately above Ep- 4 ash at the base of black organic clay at drain A10f/g. This is much older than the dates for the same fraction of the other samples in the table, which are all from the same stratigraphic stratum, the black organic clay, or the underlying one, the red-brown organic mud. The ANU-1458C date seems reliable, since wood fragments from the same sample gave an even older mean date, ANU-1458B (Table A6.2), marginally overlapping with ANU-1458C at 2 sd. 


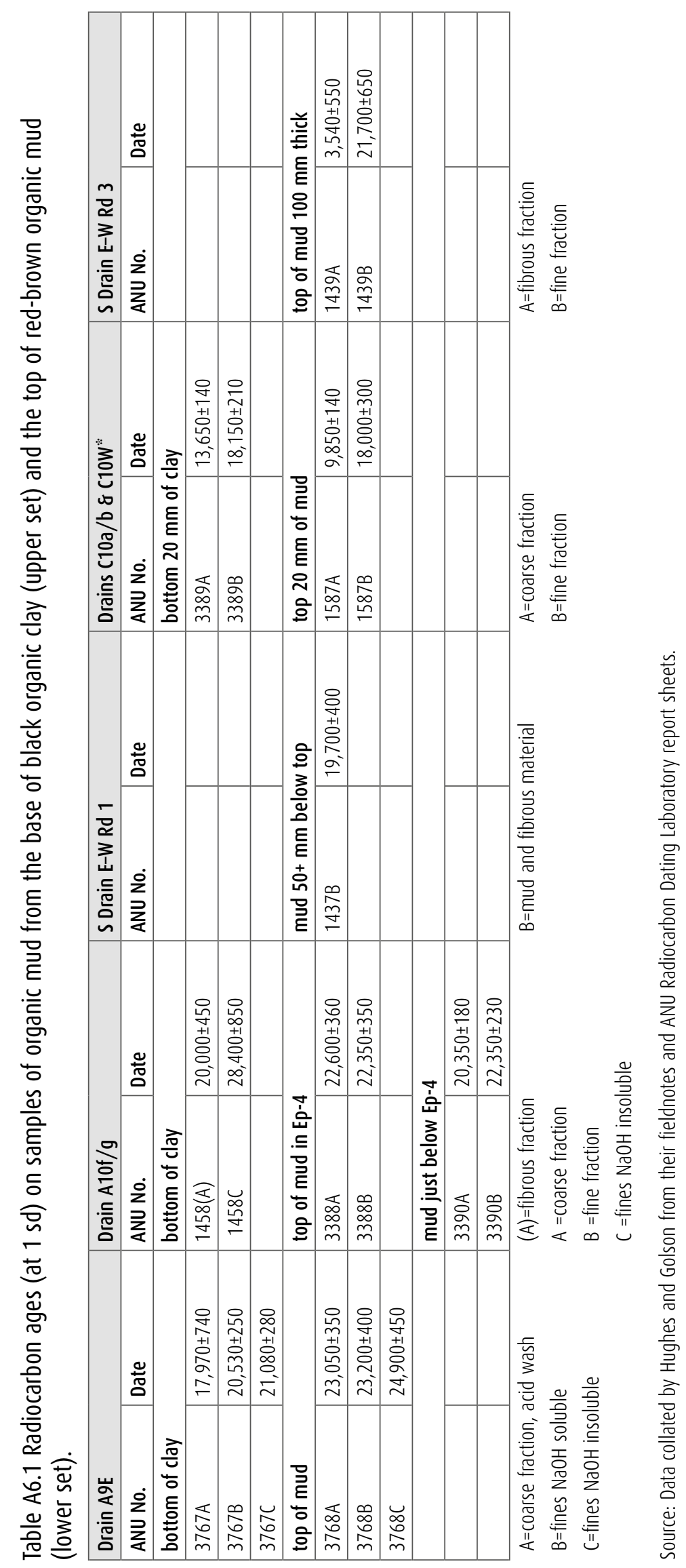


The calibrated ages of these two samples, and others on wood and charcoal pertinent to the age of the organic/inorganic transition, are presented in Table A6.2 below, rounded off to the nearest 10. All are calibrated at $2 \mathrm{sd}$, using CALIB 6.0 calib.qub.ac.uk/calib/calib.html; Reimer et al. (2009) and are shown with the per cent probability that the true date falls within the indicated age range.

Three samples of charcoal were collected at the base of black organic clay and the surface of the underlying swamp along a $10 \mathrm{~m}$ stretch of drain A9E some 60 to $70 \mathrm{~m}$ from its northern end (ANU-1195, ANU-3187 and ANU-3188) (Table A6.3). To test the date of the organic/inorganic transition, yet again samples of organic sediment were taken from the west wall of drain A9E using a sampling tin across the interface between black organic clay and organic mud at the southern end of the investigated $10 \mathrm{~m}$ stretch. The ages for the two samples, ANU-3767 for the black organic clay and ANU-3768 for the organic mud (Table A6.1), were again discrepant with the three wood and charcoal dates (Tables A6.2 and A6.3). Another dated charcoal concentration (ANU-1056) some $110 \mathrm{~m}$ to the west, on the line of drain A9c/d, correlates with charcoal dates from A9E. This concentration was $10 \mathrm{~mm}$ thick and $130 \mathrm{~mm}$ above the base of black organic clay, which here lay not on swamp but on basal volcanic ash.

Table A6.2 Calibrated ages of wood, charcoal and mud relating to the age of the organic/inorganic transition.

\begin{tabular}{|l|l|l|l|l|}
\hline Lab no. & Material & Calibrated age (cal. BP) & \% Probability & Drain \\
\hline ANU-1458B & Wood & $40,660-34,430 \mathrm{BP}$ & $(100 \%)$ & A10f/g \\
\hline ANU-1458C & NaOH insoluble fines & $34,590-31,320 \mathrm{BP}$ & $(100 \%)$ & A10f/g \\
\hline ANU-1195 & Charcoal & $35,650-31,480 \mathrm{BP}$ & $(96 \%)$ & A9E \\
\cline { 3 - 4 } & & $36,260-35,830 \mathrm{BP}$ & $(4 \%)$ & \\
\hline ANU-3187 & Charcoal & $36,850-31,200 \mathrm{BP}$ & $(100 \%)$ & A9E \\
\hline ANU-3188 & Charcoal & $36,520-32,240 \mathrm{BP}$ & $(100 \%)$ & A9E \\
\hline ANU-1056 & Charcoal & $37,430-33,020 \mathrm{BP}$ & $(100 \%)$ & A9b/c \\
\hline
\end{tabular}

Source: ANU Radiocarbon Dating Laboratory reporting sheets.

Collectively, these six dates, four on charcoal, one on wood and one on $\mathrm{NaOH}$-insoluble fines, indicate a minimum age for the organic/inorganic transition of between 41,000 and 31,000 years ago, on the basis of which we suggest a generalised date of 35,000 years ago. The dates on clay and mud that, with one exception (ANU-1458C), are more recent than the wood and charcoal samples are rejected on the grounds of younger contamination. Bulk organic samples collected for dating are more susceptible to contamination because they may contain a mixture of organic particles from unknown sources of carbon, which of course could be younger, older or both.

\section{The earliest human presence at Kuk}

We think that the four occurrences of charcoal dated to between about 37,000 and 31,000 cal. years BP (ANU-1056, ANU-1195, ANU-3187 and ANU-3188) are likely to be evidence of the earliest human presence at the swamp at Kuk. One of them, ANU-3188, was collected from what was interpreted as a scoop hearth. All occur along what would have been the southern margin of the swamp at the time.

Golson (2000: 242) has argued a case for pandanus exploitation at Kuk in the Late Pleistocene, on a number of grounds. In samples from the black organic clay, Powell (1984) had found evidence of firing of the vegetation and identified pandanus pollen there, as well as in the underlying organic swamp, where, in addition, a few drupes of $P$. antaresensis were discovered during drain digging. Also found during drain digging, more likely, it was thought, on the top 
of the organic swamp rather than in it (Golson 2001: 192), was the butt end of a waisted axe, an implement plausibly associated with pandanus exploitation (Golson 1991a: 87-88). More recent work supports this interpretation of the Late Pleistocene evidence at Kuk (see Chapters 9 and 10) and the radiocarbon data reviewed above have supplied a firmer chronology.

The organic/inorganic transition, for which we propose a date of around 35,000 years ago on the basis of the consistent charcoal and wood ages of around 30,000 radiocarbon years, may reflect the appearance of a different depositional regime at the swamp that made its margins habitable.

\section{Younger wood dates at the organic/inorganic transition}

There are two additional dates on wood (cellulose), however, that are much younger than 35,000 years, ANU-1437A and ANU-1438 of Table A6.4. The wood samples were both from the top of the organic swamp and they date appreciably closer to the mud and clay samples at the organic/ inorganic transition (Table A6.1) than to the wood and charcoal samples (Table A6.2). Both are from the south drain of E-W Rd 1. Sample ANU-1437A was close to the eastern boundary of the Station at block A12e and ANU-1438 was further west at block A12b. Henry Polach, who was then head of the ANU Radiocarbon Laboratory, wrote on the laboratory report sheet that ANU-1437A was not significantly different, statistically, from the date for ANU-1437B obtained from the mud and fibres in which the wood had been embedded (Table A6.1). This, he said, was because of the large statistical error associated with the cellulose result, ANU-1437A.

Table A6.3 Radiocarbon ages (at $1 \mathrm{sd}$ ) on wood or charcoal from the bottom of black organic clay.

\begin{tabular}{|c|c|c|c|c|c|}
\hline \multicolumn{2}{|c|}{ Drain A9c/d } & \multicolumn{2}{|c|}{ Drain A9E } & \multicolumn{2}{|c|}{ Drain A10f/g } \\
\hline \multicolumn{2}{|c|}{$80 \mathrm{~m} \mathrm{~S}$ of E-W Rd 1} & \multicolumn{2}{|c|}{ collection area as in Table 1} & \multicolumn{2}{|c|}{ collection site as in Table A6.1 } \\
\hline ANU No. & Date & ANU No. & Date & ANU No. & Date \\
\hline \multirow[t]{5}{*}{$1056 x$} & $30,740 \pm 980$ & $1195 x$ & $29,400 \pm 1,100$ & 1458B & $32,350 \pm 1,450$ \\
\hline & & \multicolumn{2}{|c|}{ recollection of above } & & \\
\hline & & $3187 y$ & $29,650 \pm 1,440$ & & \\
\hline & & \multicolumn{2}{|c|}{ from scoop hearth a few $m$ to the $S$} & & \\
\hline & & $3188 x$ & $30,000 \pm 950$ & & \\
\hline \multicolumn{2}{|c|}{$x=$ charcoal, acid wash } & $\begin{array}{l}x=\text { charcoa } \\
y=\text { charred }\end{array}$ & & \multicolumn{2}{|c|}{$B=$ cellulose fraction } \\
\hline
\end{tabular}

Source: Data collated by Hughes and Golson from their fieldnotes and ANU Radiocarbon Laboratory report sheets.

Table A6.4 Radiocarbon ages (at $1 \mathrm{sd}$ ) on cellulose from wood at the top of red-brown organic mud on E-W Rd 1.

\begin{tabular}{|l|l|l|}
\hline ANU No. & Date & Collection point \\
\hline $1437 \mathrm{~A}$ & $23,950 \pm 1,600$ & $90 \mathrm{~mm}$ diameter log lying $50 \mathrm{~mm}$ below top of swamp (cf. ANU-1437B of Table A6.1) \\
\hline 1438 & $23,100 \pm 600$ & $\begin{array}{l}\text { Root at base of tree stump over which the swamp mud/black clay boundary arches, } \\
\text { as does Rom ash, which is displaced upwards by } 100 \mathrm{~mm}\end{array}$ \\
\hline
\end{tabular}

Source: Data collated by Hughes and Golson from their fieldnotes and ANU Radiocarbon Laboratory report sheets.

One possible explanation is that these two younger samples of wood have intruded from above into older deposits. This could easily be the case if they were the roots of trees growing in younger deposits above. It is perhaps worth noting that at the collection sites of ANU-1437 and ANU1438, the ash identified as Rom was $70 \mathrm{~mm}$ and $40 \mathrm{~mm}$ respectively above the top of the swamp mud, which is much less than at other collection spots recorded: around $200 \mathrm{~mm}$ at A9E, $300 \mathrm{~mm}$ at A10f/g and about $200 \mathrm{~mm}$ at D7d/e. There are a number of possible reasons for this, 
including a slower local rate of deposition or the local occurrence of erosion at the collection sites of ANU-1437 and ANU-1438 on E-W Rd 1, or the possibility that the transition itself may have varied in date in some places in the swamp.

\section{The age of the underlying swamp as $>50,000$ calendar years}

This age is based on ANU-1440, on a sample of cellulose from the wood of a $100 \mathrm{~mm}$ diameter $\log$ at block C7b on E-W Rd 3 lying about half a metre below the organic/inorganic transition. The ANU laboratory reported the age in September 1975 as 'background', i.e. beyond the range of radiocarbon dating, a result about which Henry Polach wrote in pencil on the report sheet 'older than 50,000'. 
This text is taken from Ten Thousand Years of Cultivation at Kuk Swamp in the Highlands of Papua New Guinea, edited by Jack Golson, Tim Denham, Philip Hughes, Pamela Swadling and John Muke, published 2017 by ANU Press, The Australian National University, Canberra, Australia. 